\title{
$\mathbf{X}$.
}

\section{Beiträge zur normalen und pathologischen Anatomie der Arterien.}

\author{
Von Dr. Th. Langhads, \\ Assistenten am pathologischen Institnte zu Würzburg.
}

(Hierzu Taf. v.)

\section{Zur normalen Anatomie der Intima der Arterien.}

Die nachfolgenden Untersuchungen sind besonders auf die Frage nach dem Vorhandensein von Zellen und deren Gestalt in der normalen Intima der Arterien gerichtet. Schon lange sprechen die pathologischen Histologen von sternförmigen Zellen in der verdickten Intima, und es finden sich auch hier und da Angaben über ähnliche Zellen in der normalen Membran. Doch sind die letzteren, da ein exacter Nachweis der Zellen nicht geführt war, von den Bearbeitern der normalen Histologie ausser Acht gelassen worden. Zudem bezogen sich dieselben mehr auf die fettige Entartung dieser Zellen, in welchem Falle die Fettröpfchen, in sternförmigen Figuren zusammengruppirt, die Gestalt der intacten Zellen andeuten sollten. So bei Virchow, Cellularpathologie 3. Aufl. 323. Freilich konnte man dieser Behauptung entgegenhalten, dass das Fett in sternförmigen Lücken abgelagert sei; ein Einwurf, welchem Virchow durch das Läugnen jeglicher Lücken im Bindegewebe im Allgemeinen und in der Arterienintima im Besonderen begegnete.

Kölliker fasst den neuesten Standpunkt unserer Kenntniss von der Intima folgendermaassen zusammen (Gewebelehre 1863, S. 587): „Ein eigenthümliches Fasergewebe enthält die Intima der stärkeren Gefässe, welches seit Henle allgemein als umgewandeltes Epithel angesehen wird. Es sind blasse, meist streifige, auch wohl gleichartige Lagen mit länglichen, der Längenaxe der Gefässe gleich verlaufenden (längsovalen) Kernen, welche nicht selten in schmale spindelförmige Fasern jede mit einem Kerne, ähnlich ge- 
wissen Epitheliumzellen, oder wenigstens in Fasern sich zerlegen lassen, andere Male aber auch mehr gleichartig und kernlos vorkommen oder selbst in ganz feine Faserhäute, wie die dichtesten, feinsten elastischen Netze sich umzuwandeln scheinen. Die Aehnlichkeit dieser Lagen, die ich die streifigen Lagen der Intima nennen will, oder vielmehr der ihnen zu Grunde liegenden Faserzellen mit den Gefässepithelien, berechtigt noch nicht, sie aus dem letzteren abzuleiten, indem keine Thatsache beweist, dass die wirklichen Epitheliumzellen und die streifgen Lagen in einem näheren Zusammenhange stehen, in der Art, dass die letzteren einmal wahres Epithel und innerste Gefässlage waren, dann allmählich nach aussen ruickten und in ihren Elementen verschmolzen, dagegen scheint es auch mir erlaubt, die Epitheliumzellen und die Bildungszellen der Lagen als ursprünglich gleichwerthige Zellen anzusehen, die jedoch im Laufe der Entwickelung die einen in dieser, die anderen in jener Richtung sich umwandeln und so schliesslich zu mehr oder weniger verschiedenen Geweben werden." Ganz dieselbe Darstellung mit denselben Worten findet sich in der 9 Jahre früher erschienenen mikroskopischen Anatomie (1854. II., 2, 497 u. ff.) desselben Verfassers.

$\mathrm{Zu}$. meinen Untersuchungen habe ich besonders die Aorta ascendens benutzt. Sie wurde sehr verschiedenen Bebandlungsmethoden unterworfen; zunächst trocknete ich meist ein Stück, um auf Dickenschnitten Aufschlüsse über die Dicke der Intima zu erhalten. Flächenschnitte, welche allein brauchbar sind, um das Vorhandensein und die Gestalt zelliger Elemente zu bestimmen, an der frischen Aorta verfertigt, habe ich mit Carminimbibition und darauf folgender Essigsäurebehandlung bei älteren Leuten wie bei jungen Kindern untersucht. In der Intima der Aorta eines 50- bis 60jährigen Mannes, welche, wie Dickenschnitte des getrockneten Präparates zeigten, 0,08-0,12 Mm. dick war, traten nach dieser Methode besonders deutlich hervor rundliche granulirte Körperchen, $0,004 \mathrm{Mm}$. im Durchmesser, scharf contourirt, mit einem eigenthümlichen Glanz; sie lagen ziemlich dicht, $2-4$ nebeneinander oder in gegenseitigen Abständen von 0,008-0,016 Mm. 0b diese körperchen Zellen oder freie Kerne waren, liess sich nicht entscheiden; wir werden später sehen, dass sie das erste Zeichen einer beginnenden Verdickung der Intima sind, und ich werde sie 
daher, als mehr dem pathologischen Theil meiner Untersuchungen angehörig, vorläufig ausser Acht lassen. Neben diesen sieht man jedoch noch andere Körperchen, von ansehnlicherer Grösse, ovaler, gebogener, oft etwas eingeknickter Gestalt, 0,015-0,018 Mm. lang und $0,003-0,01 \mathrm{Mm}$. breit, oder wenn von mehr rundlicher Gestalt, doch von ähnlichem Volum. Ihr äusserer Contur ist dunkel, scharf, ihr Inhalt hell, etwas körnig, entbehrt des Glanzes und ist durch 1 oder 2 dunkle punktförmige Körperchen ausgezeichnet; es sind diess offenbar die Kerne, welche nach Kölliker in schmalen, spindelförmigen Fasern liegen sollen. Das Letztere ist jedoch nicht oder wenigstens nicht regelmässig der Fall. Denn diese Kerne liegen, soviel sich sogar nach dieser Methode erkennen lässt, selten frei in der körnigen Grundsubstanz, sondern sind von einer blass imbibirten Substanz umgeben, welche gern die Sternform anzunehmen, ja hier und da selbst in Ausläufer sich fortzusetzen scheint; nach aussen ist dieselbe nicht scharf begrenzt und fehlt selbst manchen Kernen ganz, so dass das Bild wenig Vertrauen erweckend ist. Bei längerem Liegen in Glycerin wird das Präparat, wie ich gefunden habe, deutlicher und jetzt zeigt mir ein solches schon ein ganz hübsches Ausläufernetz, das vor $\frac{1}{2}$ Jahr nur hier und da andeutungsweise zu sehen war. Ich habe, um über diese Verhältnisse genaueren Aufschluss zu erhalten, verschiedene andere Methoden angewandt, welche auch sonst gebräuchlich sind, um in bindegewebigen Theilen zellige Elemente deutlich zu machen; so das Kochen in reinem Wasser, in sehr verdünnter $(0,2-1$ pCt.) Essigsäure, Salzsäure und Salpetersäure, längere Maceration in diesen Säuren, so wie in Holzessig. Doch keine dieser Methoden führte mich zum Ziel. Weder wird die Grundsubstanz stark genug aufgehellt, noch werden die Zellen durch Mittheilung einer dunkleren Farbe deutlicher gemacht; die frische Intima habe ich noch günstiger gefunden als solche Präparate. Die einzige Conservirungsflüssigkeit, deren ich mich mit Vortheil bedient hàe, ist die bekannte Müller'sche Augenflüssigkeit, welche ich schon früher zum Darstellen der Sehnenzellen benutzte. Wenige Tage genügen, um den vortheilhaften Einfluss derselben hervortreten zu lassen. Doch schadet es weiter nicht, wenn man die Aorta noch länger, bis mehrere Wochen und Monate darin liegen lässt. Unumgänglich nothwendig ist dabei die nachherige Anwendung von Carmin, um die blassen Zellen 
durch Imbibition von der Grundsubstanz unterscheiden zu können; ich babe die besten Bilder erhalten, wenn jch die Flächenschnitte solcher Aorten einen, ja mehrere Tage lang in eine recht verdünnte Carminlösung legte; weniger gut waren die durch rasche Imbibition in einer stärkeren Lösung erhaltenen Präparate. Feine Flächenschnitte der oben erwäbnten Aorta des 50-60jährigen Mannes zeigen an geeigneten Stellen ein dichtes Zellennetz, welches sehr blass erscheint und sich nur durch die Carminfärbung von der kaum gerötheten Grundsubstanz unterscheidet. Freilich ist es schwer, dasselbe in seine Einzelheiten zu verfolgen, da selbst an den dünnsten Schnitten mehrere Zellenlagen übereinander liegen, wie man leicht daran erkennen kann, dass die Ausläufer der Zellen einander kreuzerr, ohne zu anastomosiren. Es ist also wegen der dünnen Beschaffenheit der Schichten der Intercellularsubstanz, welche die einzelnen Zellenlagen trennen, fast unmöglich, die Zellen einer Schichte von denen einer tieferen oder höheren zu unterscheiden. Am deutlichsten sind die Kerne, die etwas weniger stark imbibirt sind, als die Zellsubstanz, und in ihrer. Mitte einen körnigen Inhalt nebst 1 bis 2 dunkle Kernkörperchen zeigen. Ihre Form ist meist eine ovale, längliche, sich selten stark der rundlichen nähernde; ihre Grösse beträgt $0,004-0,005 \mathrm{Mm}$. in der Breite und etwa 0,01 Mm. in der Länge. Meist ist ein Kern in einer Zelle, doch fand ich auch zwei; diese waren dann mehr rundlich und kleiner, 0,005 Mm. im Durchmesser, oder 0,007 Mm. lang und $0,005 \mathrm{Mm}$. breit. Das Verhältniss des Kerns zu der Zellsubstanz ist der Art, dass beide gewöhnlich an Masse einander gleichstehen und die Zellsubstanz dem Kern entweder an einer Seite anliegt (was das Häufigere ist) oder ihn gleichmässig umgibt. Die Zellsubstanz ist dunkler imbibirt, erscheint mehr homogen als körnig; nach aussen ist sie nicht immer durch einen scharfen Contur begrenzt, sondern der Uebergang in die Intercellularsubstanz ist manchmal ganz allmählich, verschwimmend; hier und da finden sich in inr kleine Fetttröpfchen. Die ganze Gestalt der Zellen wird nun bedingt durch die von ihr ausgehenden Ausläufer, und in dieser Hinsicht bieten sich grosse Verschiedenheiten dar, wie bei den Hornhautkörperchen, an die man sofort erinnert wird. Die Zahl der Ausläufer schwankt zwischen 2 und 8, gewöhnlich sind es deren 3,4 oder 5 . Sie zeichnen sich durch ihren langen, sehr 
graden Verlauf, wie durch weitere Verästelung aus; ihre Breite wechselt sehr, von 0,0006-0,003 Mm.; an der Stelle ihrer Anastomosen und Verästelungen bilden sie eine kleine dreieckige Anschwellung; ebenso erweitern sie sich trichterähnlich bei ihrem Ansatz an die Zelle. Letztere erhält dadurch je nach der Zahl der sich ansetzenden Ausläufer eine Spindelform oder eine 3-oder 4eckige etc. Gestalt. Die Substanz der Ausläufer gleicht in ihrem Aussehen ganz der Zellsubstanz, und sie lässt sich im undeutlich faserigen Grındgewebe ebenfalls nur durch stärkere Carminimbibition erkennen; sind die Ausläufer sehr dünn und blass, so entgehen sie zuletzt der Beobachtung ganz, und scheinen frei im Gewebe zu enden; ob diess wirklich der Fall ist, lässt sich natürlich nicht sicher bestimmen. Dass sie dagegen benachbarte Zellen untereinander verbinden; ist meistens leicht festzustellen. Zellen und Ausläufer liegen so dicht, dass die Intercellularsubstanz nur an ganz dünnen Schnitten in bedeutender Menge hervortritt, an dickeren Schnitten aber verschwindet. Welchen Einwurf man diesen Bildern machen könnte, um die Existenz der Zellen in Frage zu stellen, wilsste jch in der That nicht; die Deutung derselben liegt zu sehr auf der Hand. Chemische Isolationsmethoden habe ich daher auch ganz ausser Acht gelassen. Dagegen will ich noch erwähnen, dass es mir an mehreren Schnitten gelungen ist, diese Zellen mechanisch durch vorsichtiges Zerzupfen $z u$ isoliren, ja selbst noch bedeutende Bruchstücke des Ausläufersystems mitzuerbalten:

Auf diese Weise habe ich die Intima der Aorta von sehr verschiedenem Alter untersucht, und es gelang mir, die Zellen deutlich noch bei einem 10jährigen Knaben zu sehen. Da die Intima in der Jugend dünner ist als im Alter, und ferner die streifigen Lagen Kölliker's bei jungen Individuen undurchsichtiger sind, als bei älteren, so wächst, je jünger das Individuum ist, auch die Schwierigkeit der Untersuchung. Bei einem 4 Tage alten Kinde fand ich in der körnigen und nicht sehr durchsichtigen Grundsubstanz hier und da ovale Kerne, 0,005 Mm. breit und 0,01 bis 0,015 Mm. lang, mit dunkler scharfer Begrenzung und körnigem Inhalt in der Mitte; dieselben waren nie vollständig isolirt, sondern an ihren beiden Enden fanden sich in der Richtung der Längsaxe faserartige Anhänge, blass imbibirt und von homogenem oder kör- 
nigem Aussehen, bis 0,01 Mm. lang; sie verschmälern sich plötzlich an einer Stelle und sind dann noch eine Strecke weit verfolgbar; es scheint also die Mebrzahl der Zellen spindelförmig au sein; nur an einigen wenigen lag die imbibirte Masse (Zellsubstanz) den Kernen seitlich und nicht ihren spitzen Enden an. An dünnen Dickenschnitten der getrockneten Aorta sah man kleine rundliche Körperchen, wie in manchen verdickten Aorten der Erwachsenen, auch nicht dichter gelegen wie bei letzteren. Das jüngste Individuum, in dessen Aortenintima ich mit Sicherheit die sternförmigen Zellen nachweisen konnte, ist wie gesagt ein 10jähriger Knabe. Die Zellen sind bei ihm dadurch ausgezeichnet, dass der Kern an Masse bedeutend vorwiegt; er ist $0,004-0,006 \mathrm{Mm}$. breit und $0,015-0,12 \mathrm{Mm}$. lang, enthält in seiner Mitte mehrere feine Körnchen, von denen sich einige durch ihre Dunkelheit auszeichnen; ein grosses glänzendes Kernkörperchen aber lässt sich nieht erkennen. Die Zellsubstanz ist blass, wenn auch etwas stärker imbibirt als der Kern, erscheint gleichmässig homogen oder nur sehr feinkörnig; sie findet sich nur in geringer Menge, oft nur an den Ansätzen der Ausläufer in etwas beträchtlicherer Masse angehäuft, selten gleichmässig um den Kern vertheilt. Die äussere Begrenzung derselben ist blass und körnig, selten eine scharfe dunkle Linie. Die Zabl der Ausläufer variirt auch hier von 2-8; spindelförmige Zellen mit 2 Ausläufern sind ziemlich hăufig. Die Veränderungen, die im weiteren Alter an den Zellen vor sich gehen, betreffen hauptsächlich die Zellsubstanz und Ausläufer. Die Kerne zeigen im höchsten Alter noch dasselbe Ausseben und dieselbe Grösse, wie bei dem 10jährigen Knaben. Die Zellsubstanz nimmt dagegen an Masse zu, ebenso wie die Zahl der Ausläufer, so dass im höheren Alter spindelförmige Zellen sich im Ganzen selten finden.

Es gibt ausser dieser Methode noch eine zweite, um das Zellennetz schön und deutlich zur Anschauung zu bringen, welche ich hier noch des Ausführlicheren erwähnen will. Es ist diess die beliebte, aber in ihren Ergebnissen noch sehr streitige Versilberungsmethode. Ich babe eine sehr dünne Lösung, 6 Gran Arg. nitr. auf 5 Unzen Wasser, angewandt und mich auch hierbei der Aorta des Menschen bedient, welche sehr verschiedene Zeit nach dem Tode in jene Lösung gelegt wurde, ohne dass ich einen 
Unterschied in der Wirkung bemerken konnte, wenn ich die Aorta schon 5 Stunden nach dem Tode aus der Leiche nahm oder erst 36 Stunden in jedem Falle. Auch die Zeit, während welcher die Aorta in der Silberlösung an einem dunklen Orte lag, schwankte zwischen 5 und 24 Stunden. Diess hat insofern Einfluss, als bei 5stündigem Liegen in Silberlösung nur die oberflächlichste Schicht der Intima leicht gebräunt und bei $20-24$ stündigem Liegen die Einwirkung sich auf die ganze Intima, jedoch nur selten, auch bei normaler Dicke jener, auf die oberflächlichsten Schichten der Muscularis erstreckt. Die Art der Einwirkung war insofern versehieden, als in dem einen Fall eine mehr oder weniger intensive, aber gleichmässig braune Färbung der Intercellularsubstanz auftritt, in welcher das Zellennetz sich wie ein System heller leerer Kanäle ausnimmt, oder als die Intercellularsubstanz einen mehr oder weniger grobkörnigen schwarzen Niederschlag enthält. Die letzte Wirkungsweise gibt, da der Niederschlag sich nicht auf die Grundsubstanz beschränkt, sondern auch in den Zellen selbst sich sparsamere Silberkörnchen finden, weniger schöne Präparate; auch treten wegen der nicht sehr dichten Lage der Silberkörnchen die Zellengrenzen nicht so scharf hervor. Einen Niederschlag in den Zellen bei Freibleiben der Intercellularsubstanz vermochte ich nicht zu erzeugen, wie diess von His durch Einwirken von Kochsalzlösung bei den Hornhautkörperchen geschehen ist. Das Bild, welches man nach dieser Methode auf Flächensehnitten einer normal dicken Intima erhält, ist, wie die beigegebene Abbildung (Fig. 5) zeigt, ein genaues Abbild des vorhin beschriebenen Zellennetzes. Von der mehr oder weniger dunkel gebräunten Grundsubstanz hebt sich ein scharf begrenztes Kanalsystem mit hellem durchsichtigen Inhalt $a b$, an welchem man sofort $z$ wei Abschnitte erkennen kann, feine, verschieden lange, unter einander anastomosirende Kanäle von unregelmässig zackigem oder gebogenem Verlauf und grössere Lïcken, gleichsam Sammelpunkte dieser Kanäle, indem 3-6 der letzteren in diese einmünden; die Lücken gleichen an Gestalt und Grösse ziemlich den eben beschriebenen Zellen, so dass der Gedanke, beide für identisch zu balten, ziemlich nahe liegt. Zwischen den einzelnen Bildern ist nur insofern ein Unterschied, als die Weite der Kanäle und der braunen Maschen sehr verschieden ist; manchmal sieht man sehr lange Kanäle von $0,01 \mathrm{Mm}$. Weite, wie man 
selten Ausiäufer in der normalen Intima findet; dabei werden natürlich die Maschen enger, und das ganze Bild entfernt sich etwas von dem Eindrucke, den man bei Betrachtung der durch Müller'sche Flüssigkeit sichtbar gemachten Zellennetze erhalten hat; an anderen Stellen sieht man wieder die schönsten Zellen mit dem feinen Ausläufersystem; Kerne sind nirgends sichtbar, auch nicht nach Anwendung von Essigsäure. Die Abbildungen, theils der normal dicken, theils der verdickten Intima entnommen, uberheben mich der weiteren Beschreibung und ich kann sofort auf die Besprechung der streitigen Punkte eingehen. Bekanntlich hat sich gleich beim ersten Auftreten der Versilberungsmethode ein Meinungsunterschied gezeigt, indem His die hellen Netze für die Zellen, v. Recklinghausen dagegen für ein Kanalwerk angesehen wissen will, in dem die Zellen liegen. Zur Erledigung dieser Frage kommt. es vor Allem darauf an, neben diesem durch die Silberwirkung erzeugten. Kanalsystem an demselben Präparate noch die Zellen zur Anschauung zu bringen. Ich babe mich hier mit grossem Vortheile ebenfalls der'Müller'schen Flüssigkeit bedient, in welche die durch Silber gebräunten Präparate noch einige Tage lang gelegt wurden und zuletzt imbibirte ich die Schnitte ausserdem noch in einer dünnen Carminlösung; bei diesen Untersuchungen habe ich ausschliesslich aus später zu erörternden Gründen die verdickte Intima benutzt. Fertigt man nun einen Schnitt aus der Gegend der beginnenden Silbereinwirkung an, so kann man an diesem sehr schön die dadurch hervorgebrachten Veränderungen schrittweise verfolgen. Die erste Wirkung des Silbers sebeint die zu sein, dass die Kerne in den Zellen unsichtbar werden, wenigstens war es mir an so behandelten Präparaten nicht möglich, denselben noch in den Zellen zu erkennen, selbst in Gegenden, in. denen an dem Intercellular. gewebe noch keine Veränderung eingetreten war; dagegen erschei. nen die Zellen daselbst noch sehr scbön rotb imhibirt, von leich körnigem Aussehen. Die erste sichtbare Verănderung an der Inter. cellularsubstanz ist eine gelbe bis gelbbraune Färbung, die zuers an der Grenze der Zellen hervortritt, letztere werden dadurch na türlich viel schärfer begrenzt; auch später bleibt die Grenze zwi schen Zelle und Intercellularsubstanz immer am dunkelsten, wäh rend die Mitte der Maschen etwas heller ist. Dasselbe Verbältnis zeigt sich, wenn statt der diffusen braunen Färbung ein körnige 
Niederschlag erfolgt. An einigen Stellen findet man die Färbung bloss auf die Zellengrenzen beschränkt, so dass die Maschen bell bleiben. Wenn man in diesem Falle nicht Carminlösung anwendet, so kann man das Bild nur schwer enträthseln, jedoch ist die Grenzlinie nach den Zellen hin meist scharf gezogen, während sie nach der Mitte der Maschen hin mehr verwaschen ist. Erst später tritt die braune Färbung in der Mitte der Maschen auf und man erhält dann ein Bild, welches schon ganz den Eindruck des Kanalsystems macht, nur sind die Kanäle nicht bell, sondern mit einem deutlichen körnigen Inhalt versehen, welcher schön roth imbibirt ist. Obgleich die Kerne unsichtbar sind, so beweist doch alles diess, dass wir hier diejenigen Gebilde vor uns haben, welche wir oben nach den durch die Müller'sche Flïssigkeit erhaltenen Resultaten als sternförmige Zellen bezeichneten. Die Kanäle gehen direct in das Zellennetz des intacten Gewebes über, namentlich muss ich diesen directen gegenseitigen Uebergang von đen äusseren Conturen der Ausläufer und Zellen einerseits und denen der anscheinenden Kanäle andererseits behaupten. Erst, wenn die Färbung der Maschen einen gewissen Grad erreicht bat, treten an den Zellen und Ausläufern diejenigen Veränderungen auf, welche sie als hohles Kanalsystem erscheinen lassen. Ihr Inhalt hellt sich mit einem Male auf, das körnige Aussehen versehwindet, und ein eigenthümlicher Glanz legt sich sofort über das ganze Netzwerk, ohne dass $z$ wischen den breiteren Knotenpunkten und den engeren Kanälen in dieser Beziehung ein Unterschied zu bemerken wäre. Vielleicht tritt zugleich damit auch eine Erweiterung des Kanalsystems auf; wenigstens schien es mir an manchen Schnitten so, während ich an andern diess nicht beobachten konnte.

Die Gründe, die v. fiecklinghausen für seine Ansicht anfürt, sind besonders von der Existenz beweglicher Zellen in der Hornhant hergenommen, und von der Nothwendigkeit eines Kanalsystems als Bedingung für deren Bewegung. Für dieses Kanalsystem hält er nun das durch Silber darstellbare helle Netz und erklärt als mit ihm identisch alle auf andere Art darstellbaren, besonders durch die chemische Isolation gewonnenen, anastomosirenden sternförmigen Gebilde; durch die zum Isoliren angewandten Säuren entstände in dem mit lymphoider Flüssigkeit gefüllten Kanalsysteme ein Niederschlag, welcher als Abguss desselben bei Auflösung der 
Intercellularsubstanz zurückbleibe. Dieser Einwurf erscheint allerdings bei den sehr starken Säuren, der concentrirten oder nur wenig verdünnten Schwefel- und Salzsäure, die man zur Auflösung der Intercellularsubstanz benutzt, gerechtfertigl, obgleich man Zweifel darüber hegen konnte, dass in einer dem Blutserum oder der Lymphe ähnlichen Flüssigkeit, also in einer sehr verdünnten Eiweisslösung ein so massenhafter Niederschlag entslünde, welcher das von der Flussigkeit erfüllte Kanalsystem wie einen Abguss vollständig ausfíllte. Durch Müller'sche Flüssigkeit aber entsteht in solchen eiweisshaltigen Flüssigkeiten kein Niederschlag, auch nicht nach längerer Einwirkung, und ich halte es für erlaubt, die sternförmigen Gebilde, welche man aus der Intima nach Behandlung mit M üller'scher Flüssigkeit mechanisch isoliren kann, für in sich cohärente präexistirende Gebilde, für Zellen zu halten, und dass diese Zellen mit dem durch Silber darstellbaren Kanalsystem identisch sind, habe ich oben nachgewiesen. Als weiteren Beleg für letztere Behauptung führe ich noch an, dass auch bei der fettigen Degeneration sich jene hellen Kanäle ganz wie die eigentlichen Zellen verhalten, indem die Felttröpfchen in ihnen auftreten, zugleich in den Knotenpunkten und den feineren Kanälen, und sie vollständig bis an die scharfe Grenze der Intercellularsubstanz ausfüllen, ohne dass $z$ wischen ihnen und letaterer ein Zwischenraum bliebe. Ich will hiermit übrigens úber die in anderen Geweben darstellbaren "Saftkanälchen " kein Urtheil abgeben, sondern halte es für nothwendig, für jedes einzelne Gewebe die Bedeutung derselben besonders festzustellen.

Es ergibt sich aus dem Mitgetheilten zunächst, dass wir die ältere Ansicht Henle's, die Arterienintima für umgewandeltes Epithel zu halten, verlassen müssen. Die Intima reiht sich vielmehr hiernach der grossen Gruppe des Bindegewebes an, da wir in -ihr alle Elemente desselben, Zellen, faserige Intercellularsubstanz mit reichlichem elastischen Gewebe, nachweisen können.

lch füge noch einige andere Resultate an, die ich bei obigen Untersuchungen nebenher gewonnen habe. Die Dicke der Intima ist grossen Schwankungen in den verschiedensten Lebensaltern, besonders in den höheren, unterworfen, wie die unten folgenden Zahlen beweisen; diese geben jedesmal die geringste Dicke an, die ich finden konnte. Zugleich habe ich zur Vergleichung die 
Dicke der Muscularis beigeftigt. Alle Masse sind an in verdünnter Essigsäure aufgeweichten Schnitten der getrockneten Aorta ascendens gewonnen.

\begin{tabular}{|c|c|c|c|}
\hline \multirow{2}{*}{\multicolumn{2}{|c|}{ Alter. }} & \multicolumn{2}{|c|}{ Dicke der } \\
\hline & & $\begin{array}{l}\text { Intima. } \\
\text { Mm. }\end{array}$ & $\begin{array}{c}\text { Muscularis. } \\
\text { Mm. }\end{array}$ \\
\hline 4 & Tage & $0,015-0,02$ & 0,5 \\
\hline $1 \frac{1}{2}$ & Jahre & 0,025 & 0,8 \\
\hline 10 & - & $0,016-0,025$ & 0,9 \\
\hline 18 & - & $0,025-0,03$ & 1 \\
\hline 20 & - & $0,03-0,06$ & 1,2 \\
\hline 25 & - & 0,04 & 1,3 \\
\hline 27 & - & $0,03-0,04$ & 1,2 \\
\hline 35 & - & 0,06 & 1,25 \\
\hline 50 & - & $0,08-0,12$ & 1,5 \\
\hline 54 & - & $0,05-0,12$ & 1,5 \\
\hline 73 & - & 0,08 & 1,5 \\
\hline 79 & - & 0,05 & 1,5 \\
\hline
\end{tabular}

Ich habe schon oben erwähnt, dass bei jüngeren Individuen an dem Grundgewebe der Intima sich nicht die zwei Schichten Kölliker's, die gestreiften und elastischen Lagen unterscheiden lassen; die Intima ist in diesem Alter nicht deutlich faserig, sondern mehr undeutlich körnig und gleicht in Aussehen und Verhalten gegen Essigsäure und Kali ganz den elastisehen Lagen der benachbarten Muscularis, von denen sie sich nur schwer an sebr dünnen Schnitten unterscheiden lässt. Die gestreiften Lagen treten erst auf, wenn die Intima eine gewisse Dicke erreicht hat, etwa im Alter von 10 Jahren und nehmen allmählich an Dicke zu. Damit hängt wohl auch das seltene Vorkommen von Verdickungen der Intima bei jüngeren Individuen zusammen, welche bekanntlich aus einem den streifigen Lagen ähnlichen Gewebe besteben. Eigenthümlich ist die Unebenheit der inneren Oberfläche der Intima, welche ich, seitdem ich darauf achtete, fast an allen Präparaten fand, sowohl an der normal dicken Intima eines Siebenzigjährigen, als an der eines sechszehnjährigen Individuums. Man zieht zu diesem Zwecke an Aorten, die in Müller'scher Flüssigkeit gelegen, die oberflächlichsten lagen der Intima ab, die Innenfläche derselben zeigt sich dann durch bellere Furchen von verschiedener Breite und Verlauf in verschieden grosse und gestaltete dunklere Felder abgetheilt. 
Deutlicher erhält man dasselbe Bild bei der Behandlung mit Silber, welches bloss die erhabenen Felder fürbt, während die Furchen hell bleiben. Schon makroskopisch zeigt sich eine feine, helle, netzföpmige Zeichnung mit dunklen Maschen und bei schwacher Vergrösserung erkennt man, dass breitere Furchen der Queraxe der Arterie mehr parallel verlaufend, von der Breite bis zu $0,07 \mathrm{Mm}$, die Oberfläche der Intima in schmale quere Bänder theilen, weiche wiederum durch schmälere Furchen, die senkrecht oder schief auf jene verlaufen und die Breite von $0,02 \mathrm{Mm}$. erreichen, in quadratische oder mehr längliche Felder getheilt werden; zwischen beiden Arten von Furchen gibt es, namentlich hinsichtlich der Breite, viele Uebergänge. Die Furchen haben eine hellere Mitte, welche zugleich am tiefsten liegt, wie das Verändern des Focus zeigt, und allmählich in die dunklere Randzone der Felder übergebt; letztere zeigt eine leicht bräunliche Farbe, die nach der tief gebräunten Mitte der Felder zu nach und nach zunimmt: in letzterer zeigen sich auch die Kanäle der Zellen am deutlichsten und schärfsten begrenzt; gegen die Peripherie hin nimmt die scharfe Begrenzung der Zellen ab, sie wird undeutlicher, und in dem Rand des braunen Felds öffnen sich die Kanäle direct in die helle Furche. Die Breite der Felder wechselt zwischen $0,07-0,2 \mathrm{Mm}$., ihre Länge zwischen 0,07 und $0,5 \mathrm{Mm}$.

\section{Zur pathologischen Anatomie der Arterien.}

1) Fettmetamorphose der normal dicken Intima.

Von der bei der sogenannten Endoarteriitis vorkommenden Fettmetamorphose der Intima unterscheidet Virchow ) streng die Fettmetamorphose der normal dicken Intima, wo dieselbe ohne vorhergegangene Reizungszustände in dieser Membran, d. h. ohne Zellen - und Intercellularsubstanzneubildung unmittelbar aufträte. Virchow findet sie am häufigsten in der Aorta, besonders bei anämischen und chlorotischen Zuständen, ferner in der Pulmonalis, an dem vorderen Zipfel der Mitralis; die Intima nimmt ein opakes weissliches Ausseben an, es entstehen kleine prominente Flecke, deren Oberfläche zuerst glatt, dann sammtartig weich erscheint; das Mikroskop weist rundliche, ovale, leicht sternförmige Körnchen-

*) Gesamm. Abhandl. 493. Cellularpath. 3. Aufl. 322. 
körper nach; später werden durch den Blutstrom die oberflächlichen Lamellen weggerissen, und es entsteht die fettige Usur. Nach meinen Untersuchungen dürfte dieser Prozess im Ganzen seltner sein, als man gewöhnlich annimmt. Um sein Vorbandensein festzustellen, bedarf es zuerst der mikroskopischen Untersuchung, da die Dicke der Intima nur auf diese Weise bestimmt werden kann und makroskopisch eine gleichmässige vielleicht sogar hochgradige Verdickung derselben leicht übersehen wird. Hat man eine solche ausgeschlossen, so schränkt sich das Gebiet unseres Prozesses bedeutend ein. Was sein Vorkommen betrifft, so habe ich nur die Aorta darauf untersucht, jedoch nicht den Zusammenhang desselben mit chlorotischen oder anämischen Zuständen finden können. Namentlich findet man die leichteren Grade, welche makroskopisch nur schwer oder gar nicht zu erkennen sind, sehr häufig bei sonst ganz gutem Kräftezustand. Eine Stelle findet sich, an welcher die fettige Entartung sogar nur in seltenen Fällen fehlt, nebmiich die Intima, soweit sie dem freien Rand der Semilunarklappen und besonders den Noduli Arantii gegenüberliegt. So lange der Prozess sich bloss in den Zellen findet, ist er für das blosse Auge kaum zu erkennen; ist er auch auf die Intercellularsubstanz übergegangen, so erhält die Oberfläche der Intima das von Virchow erwähnte opake, weissliche oder weissgelbliche Aussehen und an den Stellen der stärksten Entartung bilden sich kleine, sammtartige, intensiv gelb gefärbte wallartige Erhebungen, die man besonders häufig dem freien Rand der Semilunarklappen gegenüber und ihnen parallel gerichtet findet. Mikroskopisch zeigt sich, dass die Fettentartung sowohl in den Zellen als auch in der Intercellularsubstanz ihren Ausgang nimmt. In den Zellen treten feine Fetttröpfehen zerstreut auf, und zwar in den Ausläufern und der Zellsubstanz zugleich; die feinen Ausläufer erscheinen au diesen Stellen etwas aufgetrieben, so wie auch die vollständig entartete Zelle einển grösseren Umfang zu haben scheint, als die normale. Nie sieht man, dass etwa eine Membran die Fettkörnchen umschliesst; immer scheinen dieselben, wenn sie an der äusseren Grenze der Zelle liegen, direct an das Intercellulargewebe zu stossen. Die vollständig entarteten Zellen behalten ibre frủhere Gestalt bei und so sieht man sternförmige oder spindelförmige, durch rosenkranzförmige Reihen von Fetttröpfchen untereinander verbundene 
Anhäufungen von Fett, deren einzelne Tropfen erst später zusammenfliessen; ihre Entstehung aus dem Zellennetz lässt sich ausser durch ihre eigenthümliche Form noch durch ihren continuirlichen Zusammenhang mit den Zellen an normalen Stellen nachweisen. Geht die Entartung von letzterem aus, so beginnt sie mit einer Entfärbung desselben; die Carminimbibition verschwindet; die Farbe des Gewebes wird gelblich und bräunlich, während die Zellen noch schön imbibirt sind; zuletzt treten Fetttröpfchen auf, oder auch ohne dass ein Zwischenstadium von Bildung flüssiger Fette aufgetreten wäre, krystallinisches Fett, welches sich durch seine Gestalt leicht als Cholestearin ausweist. Hierdurch entsteht jene wallartige Erhebung, welche bei der Dicke der benachbarten Intima von $0,025-0,03 \mathrm{Mm}$. bis $0,1 \mathrm{Mm}$. und darüber betragen kann; die Entartung findet sich in ihren höchsten Graden zuerst in der Tiefe, so dass der Heerd mit grossen Fetttropfen oder Cholestearintafeln noch von einer schmalen Schicht der Intima bedeckt wird; dass der Heerd später durchbricht, scheint mir wenigstens nicht häufig vorzukommen; denn grade den Semilunarklappen gegenüber kann ich keine Usur finden. An dieser Stelle findet sich noch zugleich nicht selten fettige Metamorphose der benachbarten Muskellagen, die durch grosse Fettropfen ersetzt werden; beide Heerde fliessen zusammen oder bleiben durch die der Intima zunächst liegenden Schichten der Muscularis noch getrennt. Eine vorhergegangene Schwellung der einzelnen Elemente, oder der Ausgangspunkt der Entartung, ob Muskulatur oder elastische Fasern, lässt sich hier nicht nachweisen.

Ich erwähne noch die Fettmetamorphose des Epithels, die nach Virchow besonders an einer grösseren Reibung ausgesetzten Stellen vorkommt, wie an den Herzklappen und an den Mündungen kleinerer Gefässäste; meist bemerkt man erst das Resultat derselben, die Zerstörung des Epithels und die Entblössung der inneren Haut, die etwas matt, trüb und leicht rauh sein soll. Es scheint danach, dass der eigentliche Prozess der Fettentartung auch von Virchow nicht beobachtet ist, da jede genauere Beschreibung desselben fehIt und dass Virchow auf sein Vorhandensein erst aus dem Mangel des Epithels geschlossen hat, dass ein solcher Mangel jenes Aussehen bedingt, kann ich nicht finden; es ist mir nicht gelungen, an der frischen Aorta die Stellen, an denen 
das Epithel fehlt, von den mit Epithel versehenen zu unterscheiden. Dass in der Aorta Erwachsener das Epithel häufig nur unvollständig vorhanden ist, auf grösseren Strecken gänzlich fehlt, ist schon lange bekannt*). Donders hat es hier sogar nie gesehen. Mittelst der Silberlösung ist es sehr leicht, sich an sorgfältig behandelten Aorten von der Richtigkeit dieser Angaben zu überzeugen; das Epithel ist an solchen nur in Form kleinerer oder grösserer Inseln sichtbar, während der grösste Theil der Intima frei liegt. An diesen Inseln sieht man aber nie Spuren fettiger Entartung der Zellen, so dass ich jene Behauptung Virchow's nicht für ganz richtig halten kann; wenn dieser Prozess auch hier und da vorkommen mag, so ist doch die Entblössung der Intima in den wenigsten Fällen Folge davon; es scheint mir, dass man sie meist einem nach dem Tode vor sich gehenden Loslösen des Epithels zuzuschreiben hat.

2) Verdickung der Intima und fettige Entartung in derselben (Endarteritis deformans s. nodosa Virchow).

Die unzweifelhaft häufigste Veränderüng der Intima der Arterien ist ihre Verdickung, welche, partiell oder allgemein, im höheren Alter fast regelmässig gefunden wird, so dass es fast unmöglich ist, hier eine normale Dicke der Intima anzunehmen. Ich habe oben erwähnt, dass jch noch bei einer 79jährigen Frau die Dicke der Intima in der aufsteigenden Aorta durchgängig nur $0,05 \mathrm{Mm}$. betragend fand. Nimmt man diese Zahl als normal an, so ist es einleuchtend, dass in der Mehrzahl der Fälle die Intima pathologisch verdickt ist.

Bei den Verdickungen hat man zunächst zwischen den allgemeinen, gleichmässigen, über grosse Strecken, oft über die ganze Aorta verbreiteten Verdickungen und den mehr circumscripten, mehr ungleichmässigen zu unterscheiden. Erstere werden meistens, namentlich in den geringeren Graden, erst auf Durchschnitten der getrockneten Aorta mit dem Mikroskope erkannt, während letztere auch dem unbewaffneten Auge nicht entgehen. Dass auch an ${ }^{2}$ der normal dicken Intima Unebenheiten der Oberfläche existiren, ist oben erwähnt. Ein weiterer Grad derselben ist es, wenn die innere

*) Kölliker, Mikroskop. Anatomie II. 2. 500 . 
Oberfläche der Intima mit kleinen warzenförmigen Verdickungen versehen ist, wie sie sich hier und da finden. Dieselben sind etwas abgerundet und niedrig, etwa $0,02-0,04 \mathrm{Mm}$. hoch und bestehen aus einem hellen durchscheinenden Gewebe mit sternförmigen und runden Zellen. Es lässt sich dadurch, dass die tieferen, unter einer solchen Verdickung gelegenen Schichten mit unverändert sind, leicht beweisen, dass jene Verdickungen bloss den oberflächlichsten Schichten angehören; es ist nicht überfiüssig, hierauf hinzuweisen, da von manchen Seiten behauptet wird, dass die Verdickung der Intima fast ausschliesslich in der Hypertrophie der tieferen Lagen berube. Solche kleinere Erbabenheiten finden sich in verschiedener Zahl und in verschiedener Dichtigkeit gelagert und werden erst bei genauer, oft erst bei mikroskopischer Betrachtung bemerkt. Durch Zusammenfliessen derselben wird die Verdickung ausgedehnter und gleichmässig; doch entsteht die gleichmässige Verdickung durchaus nicht immer aus solchen kleineren Heerden, sondern von Anfang an über grössere Strecken verbreitet. Sie erreicht wohl nie den Grad, bis zu welchem die circumscripte Verdickung sich erheben kann; ich habe sie nie mehr als $0,5 \mathrm{Mm}$., also das Zehnfache der normalen Dicke, betragen sehen. Auf der Basis dieser ausgedehnten Verdickungen entstehen nun kleinere Heerde, die sogenannten gallertigen und halbknorpeligen Platten, von meistens 1-6 Lin. im Durchmesser, welche eine viel bedeutendere Dicke, bis zu 2 bis $3 \mathrm{Mm}$., erreichen können und der Innenfläche ein sehr unebenes, höckeriges Ansehen geben; direct aus der normal dicken Intima erheben sie sich nicht. Dass zu ihrer Bildung besonders die tieferen Schichten der Intima beitrügen, während die oberflächlichen weniger betheiligt wären, kann ich nicht bestätigen; ich finde an der Grenze der Verdickung Zellenbildung in allen Schichten gleichmässig oder auch besonders in den oberflächlichen oder mittleren Lagen, seltener bloss auf die tieferen beschränkt. So wenigstens an der Aorta. Wenig anders verhält es sich an kleineren Arterien, z. B. den Arterien der Hirnbasis. An ihnen lassen sich im normalén Zustande ausser der $0,004-0,006 \mathrm{Mm}$. dicken elastischen Lamelle, welche die Intima nach der Muscularis bin begrenzt, noch die inneren streifigen Lagen von 0,008-0,01 Mm. Dicke erkennen, in denen sich nur hier und da sparsame, auf dem Dickenschnitte scheinbar spindelförmige Zellen finden. Bei Verdickungen findet 
sich nun die Zellenneubildung fast ausschliesslich in der Tiefe zwischen den streifigen Lagen und der elastischen Lamelle; auch ragt die verdickte Stelle weniger nach innen in das Lumen vor, sondern viel mehr nach aussen, die Muscularis durch Druck verdrängend und selbst bis an die verdickte Adventitia reichend, so dass wirklich die Verdickung hauptsächlich auf Rechnung der tieferen Lagen kommt. Die Verdickung ist verhältnissmässig ungleich bedeutender, als an den grösseren Gefässen; sie beträgt bei einer Dicke der normalen Intima von $0,015-0,8 \mathrm{Mm}$. und darüber, also das Sechzigfache oder eigentlich noch mehr, da ja die Verdickung fast nur die schmalen streifigen Lagen betriff; es fällt diess um so mehr auf, als hier die starken Verdickungen oft unmittelbar aus der normal dicken Intima hervorgehen, und letztere sich an der betreffenden Stelle auf dem Dickenschnitte spindel- oder sackförmig aufbläht, mit einer wenig convexen Fläche nach innen zu, mit einer stark convexen "nach aussen. Diese Verdickungen scheinen von Anfang an in toto entstanden zu sein, während sich an den grösseren Arterien auf dem Dickenschnitt manchmal die Zusammensetzung halbknorpeliger Platten aus einzelnen kleineren Heerden sehen lässt; das Gewebe ist dann in einze]ne Unterabtheilungen eingetheilt, sowohl durch elastisches Gewebe, als durch wirkliche Bindegewebsstränge, die von der äusseren zur inneren Oberfläche hinziehen und so den Verlauf der streifigen Lagen unter rechtem oder schiefem Winkel durchschneiden, die einzelnen Unterabtheilungen unterscheiden sich selbst wieder durch Reichthum der Zellen, besonders durch Fehlen oder Mangel rundicher Zellen. Häufiger als in der Tiefe sieht man diess an der Oberfläche, welche durch diese verschiedenen Heerde ein unebenes böckeriges Aussehen erhält; liegen die einzelnen Heerde dicht bei einander, so erscheint die Oberfläche wie mit narbenartigen Einziehungen bedeckt, mit zahlreichen gewundenen linienförmigen Vertiefungen mit steilem Abfall der umgebenden Wände, die noch in Falten gelegt sind.

Besonders interessant ist das Verhalten der Zellen, von denen sich zwei Arten finden, sternförmige und runde* ${ }^{*}$. Die kleinen rundlichen Zellen (Fig. 8) haben einen Durchmesser von 0,007 Mm., mit geringen Schwankungen darüber und darunter; der rundliche

*) Wedl, Beiträge zur Pathologie der Blutgefässe. 2te Abtheilung. 1863. S. 11 . 
Kern ist nach aussen scharf begrenzt; in seiner Mitte liegen mehrere dunkele Körnchen, die durch einen wasserklaren Hof von der äusseren Kerncontur getrennt sind. Letzterer bildet an manchen zugleich die äussere Begrenzung des ganzen Elements, so dass dasselbe nur ein freiliegender Kern zu sein scheint. Dasselbe gilt von einer anderen Art rundlicher Elemente, die sich von jenen durch geringe Grösse (Durchmesser von 0,004-0,005 Mm.), blasse Imbibition, einen matten Glanz und gleichmässige feine Granulation unterscheiden; diese finden sich nicht immer, und jedesmal nur sparsam, hier und da zerstreut*). An der Mehrzahl der Kerne ersterer Art aber findet sich um dieselben noch eine grössere oder geringere Menge von dunkel imbibirter, homogener und etwas glänzender oder leicht körnig erscheinender Zellsubstanz, zunächst ungleichmässig vertheilt, mehr an einer Seite angehäuft, sich uhrglasförmig von dem Kerne abhebend; Theilungen zeigen sich an solchen Elementen häufig; die Zelle wird grösser, der körnige Inhalt des Kerns gruppirt sich in zwei Häufchen; dann sieht man zwei getrennte Kerne, noch von einer gemeinsamen Zellsubstanz umgeben und im weiteren Stadium zwei selbständjge Zellen dicht nebeneinander, aber beide kleiner als die Mutterzelle. Die Hăufigkeit dieser Zellen ist sehr verschieden; sie liegen vereinzelt, besonders gern aber in Gruppen zu 3-8; an der Grenze der Verdickungen finden sie sich am häufigsten und daselbst, wenn die Intima nicht allzu dick ist, oft in allen Schichten gleich dicht, während von den sternförmigen Zellen kaum etwas zu sehen ist, meist finden sie sich aber mit letzteren zugleich, in den Maschen der Netze jener, und zwar oft in allen Schichten der Verdickungen gleich, oft ungleich vertheilt, indem einzelne Lagen sich durch besonderen Reichtbum an runden Zellen auszeichnen, während sie in anderen ganz fehlen. Die Veränderung, die sie zunächst erleiden, betrifft sowohl Zellsubstanz als Kern; erstere vermehrt sich, wird dabei blasser und gibt je nach der äusseren Form, die sie annimmt, der ganzen Zelle die charakteristische Gestalt; immer

*) Grosse Aggregate freier Kerne, wie Wedl sie beschreibt (a. a. 0.), babe ich nicht gesehen; ich möchte dieselben für die in einzelnen Schichten angehäuften rundlichen Zellen halten, deren Charakter als Zellen an getrockneten Präparaten nicht immer deutlich ist. An anderen Präparaten, die in Müllerscher Flüssigkeit gelegen, ist ihr Zellencharakter kaum zu verkennen. 
findet sie sich ungleichmässig um den Kern vertheilt, so dass letzterer an einer Seite frei zu liegen scheint. Legt sich die Zellsubstanz an zwei einander entgegengesetzten Punkten des Kerns an, so wird die Gestalt der Zelle eine spindelförmige; zugleich zieht sich dabei der Kern in die Länge; er wird oval, man sieht auch noch hier und da spindelförmige Zellen mit rundem Kern. Legt sich die Zellsubstanz mehr unregelmässig an, so entsteht die Sternform der Zelle, an der die zarten Ausläufer meist zuletzt auftreten, doch finden sich manchmal auch an runden Zellen mit sehr geringer Zellsubstanz 2-3 seitliche Ausläufer. Die Kerne solcher Zellen sind gewöhnlich auch grösser als die der runden Zellen, von ovaler Gestalt, in manchen auch rundilich. und dann wohl von derselben Grösse, wie in den runden Zellen; häufig ist die Theilung derselben. Es ist natürlich, dass man diese Formenreihe, welche man ohne Ordnung gemischt dicht nebeneinander liegen sieht, ebenso als Umwandlungsprozess der runden zu den sternförmigen Zellen wie umgekehrt betrachten kann; und es ist wahrscheinlich, dass beide Auffassungen richtig sind. In der normalen Intima finden sich wohl bloss sternförmige Zellen und ebenso in der Mitte mancher Verdickungen, während in den Stadien der beginnenden Verdickung beide Zellenarten gemiseht sind; hier findet zunächst Umbildung der sternförmigen Zellen der normalen Intima zu rundlichen stalt und dann wieder Umbildung der letzteren $\mathrm{zu}$ ersteren. Ich möchte noch an die Analogie dieses Befundes von zweierlei Formen der Zellen in demselben Gewebe mit den Entdeckungen v. Recklinghausen's über die wandernden Eiterkörperchen erinnern, und es wäre immerhin möglich, dass wir es hier, vielleicht bei jedem Wucherungsprozess im menschlichen Körper, mit denselben Verhältnissen zu thun batten, welche v. Recklinghausen an der Hornhaut des Frosches fand; die vielgestalteten Formen, welche man an den rundlichen und den diesen nahe stehenden Zellen sieht, rechtfertigen die Vermuthung von contractilen Zellen, dass sie wandern, lässt sich freilich nicht nachweisen, aber immerhin durch den Hinweis als möglich hinstellen, dass sie ebenfalls, wie die wandernden Körperchen der Hornhaut, gern gruppenweise zusammenliegen, während die Zellen, aus denen sie entstehen und zu denen sie werden, in gewissen regelmässigen gegenseitigen Entfernungen liegen, Umstände, die allerdings auch noch 
andere Erklärungen zuliessen. Was die sternförmigen Zellen anbetrifft, so zeichnen sie sich von denen der normalen Intima gewöhnlich durch Grösse und Gestalt aus. Ihre Grösse ist meistens ungleich bedeutender; die länge des ovalen Kerns beträgt bis $0,018 \mathrm{Mm}$., seine Breite halb so viel; das Kernkörperchen, allein oder zu mehreren vorhanden, ist stark glänzend, und erreicht einen Durchmesser von 0,002 Mm.; die Durchmesser der Zelle selbst erreichen die Grösse von 0,05-0,1 Mm. Die Zahl der Ausläufer ist bei den grossen Zellen wohl dieselbe wie in der normalen Intima; sie zeichnen sich aber häufig durch ihre ungeheure Breite aus, welche von $0,002-0,02 \mathrm{Mm}$. wechselt, so dass bei Silberbehandlung sich die dunkelbraunen Maschen der Intercellularsubstanz wie Inseln in einem weiten Kanalsystem ausdehnen; diess macht natürlich eine scharfe Abgrenzung des Zellkörpers unmöglich, um so mehr, als nicht in jedem Knotenpunkt des Netzes ein Kern zu erkennen ist; eigenthümlich ist diesen Ausläufern eine feine Längsstreifung, welche sie als plattgedrückte Bündel sehr feiner Fasern erscheinen lässt; manchmal löste sich auch ein solcher Ausläufer bei genauer Betrachtung in zwei, in derselben Richtung aber in verschiedener Ebene verlaufend, auf. Ferner kommt diesen Zellen eine grössere Dicke, als den normalen, zu, und alles diess sammt der Beschaffenheit der Intercellularsubstanz bewirkt, dass sie viel leicbter, oft schon an frischen Präparaten, zu erkennen sind, als die Zellen der normalen Intima; aus diesen Gründen babe ich auch die verdickte Intima zur Lösung der Streitpunkte bei der Silberbehandlung benutzt.

Die Intercellularsubstanz verhält sich meistens wie in der normalen Intima; sie besteht aus faserigen oder streifigen Lamellen, welche der Oberfläche parallel laufen, und zwischen denen sich die Netze der sternförmigen Zellen finden. Abweichungen kommen vor, sowohl hinsichtlich der Lagerung als der Zusammensetzung. Schon ron Virchow ist die Umwandlung in Schleimgewebe bei den gallertigen Verdickungen beschrieben worden; Mucin, das charakteristische Merkmal dieses Gewebes, konnte ich an den wenigen Präparaten, die mir zu Gebote standen, nicht finden; dagegen finden sich allerdings grosse Unterschiede hinsichtlich der Faserigkeit und der Imbibitionsfähigkeit. Namentlich habe ich auf Dickenschnitten in der Nähe der inneren Oberfläche das Auftreten einer vollständig 
homogenen und in hohem Grade imbibitionsfähigen Intercellularsubstanz beobachtet, welche gegen die übrige, leicht lamellöse Intima stark abstach; sie trat zuerst in der Mitte der Lamellen zwischen den einzelnen Zellenlagen auf und umgab zunächsı netzförmig helle kleine Maschen, in denen noch die Zellen sichtbar waren; später verschwanden auch letztere in der sehr dunkel imbibirten gleichmässigen Substanz. In der Lagerung tritt ausser dem oben Angegebenen insofern eine Aenderung ein, als die auf dem Dickenschnitt gewöhnlichen spindelförmigen Zellen ihre der Oberfläche parallele Lage verlassen und entweder schief gegen dieselbe laufen oder Ausläufer in die Höhe und Tiefe einander zuschicken und so auf dem Dickenschnitt ein dem lockeren Bindegewebe ähnliches Bild bewirken. Einen maschigen Bau, wie ihn Rokitansky (Lehrbuch 1856 , II., B. 308 , Fig. 22) beschreibt, habe ich nicht gesehen. Virchow wirft ihm vor, die Zellen, die in den Maschen liegen, übersehen zu haben (Gesamm. Abhandl. S. 511); ich möchte eher das, was Rokitansky als Netze der Grundsubstanz beschreibt, für die grossen Zellen mit ihren ausserordentlich weiten Ausläufern halten. Elastisches Gewebe findet sich im Ganzen nur selten stark entwickelt, wenigstens in den grösseren Gefässen, und dann nur in den der Media benachbarten Schichten; ein weiterer Grund, wesshalb die Verdickungen nicht vorzüglich auf Rechnung der tieferen Lagen kommen, sondern mehr auf die der höheren, wie diess auch Wedl (a. a. 0. S. 11) hervorhebt. Anders verbält es sich in den kleineren Arterien an der Hirnbasis, in denen sich eine hochgradige Wucherung der elastischen Elemente nachweisen lässt; die gröberen Verbäitnisse habe ich oben erwähnt; die Neubildung runder Zellen findet in der Tiefe statt, zwischen den streifigen Lagen und der sich wellenförmig biegenden elastischen Lamelle, und zwar in den Vertiefungen der letzteren; diese einzelnen Zellennester vereinigen sich zuletzt und bilden zwischen den beiden Schichten, den streifigen inneren Lagen und der elastischen Lamelle, eine dritte, die sich dureb Reichthum an runden Zellen und undeutlich gefaserte $Z$ wischensubstanz auszeichnet; zugleich nimmt auch die elastiscbe Lamelle an Dicke zu, z. B. von $0,005 \mathrm{Mm}$. auf $0,012 \mathrm{Mm}$., also um mehr als das Doppelte; die Kanälchen, welche dieselbe durchziehen, werden länger, behalten aber ihre Breite. Im weiteren Verlauf der Verdickung bildet das elastische 
Band immer die äusserste scharfe Grenze der Intima gegen die Muscularis hin, wird also stark convex nach der Adventitia hin vorgewölbt, auf der Höhe der Convexität ist sie gewöhnlich schmaler, als normal und hat einen graden Verlauf, so dass sie hier wie durch die verdickte lntima ausgedehnt und verdunnt erseheint, zumal da auch die Kanälchen in ihr weiter auseinander rulcken. An den beiden Seiten aber, wo sie allmählich zur Convexität der Verdickung ansteigt, ist sie ebenfalls verdickt und stark wellenförmig gehogen, letzleres oft in sehr hohem Grade, so dass die Ausbuchtungen desselben selbst die Höhe von $0,04-0,05 \mathrm{Mm}$. erreichen und dicht an einander liegen. Ferner gehen von der Innenfläche desselben zahlreiche elastische Fasern und Lamellen ab, welche bis $0,005 \mathrm{Mm}$. dick, die tieferen Lagen der Verdickung durchsetzen und auf der anderen Seite sich wieder mit den elastischen vereinigen; häufig sind diese Fasern so zahlreich, dass sie reichliche Netze bilden und in deren länglichen Maschen je eine spindelförmige Zelle liegt. An einem Präparat war sogar die Verdickung in zwei Schichten getheilt, indem das breite elastische Band dieselbe in ihrer Mitte durchsetzle und so von den inneren Lagen eine $0,15 \mathrm{Mm}$. dicke, nach aussen gelegene Schicht eines hellen, an elastischen Fasern reichen Gewebes abtrennte, welche ebenfalls nach der Muscularis hin durch ein sehr schmales aber continuirliches, mit dem vorigen seitlich zusammenhängendes elastisches Band begrenzt wurde; das breitere Band hatte dadurch ein eigenthïmliches Aussehen, dass es ausser einer feinen Längsfaserung sehr verschieden breit $(0,02-0,035 \mathrm{Mm}$.) war, indem der äussere Contur einen graden, der innere einen wellenförmig gebogenen Verlauf hatte; die Kanälchen sah man auch hier noch und zwar in den schmäleren Theilen des Bandes, grade als ob letzteres zwischen denselben hervorgequollen wäre. Das elastische Gewebe bildet sich also hier im Anschluss an das vorhandene; es ist diess mehr, so scheint mir, als eine Hypertrophie und nachfolgende Zerfaserung der ursprünglichen elastischen Lamelle wie als eine von dieser unabhängige Neubildung aufzufassen; in jedem Falle übrigens gebört dasselbe der Intercellularsubstanz an und ist nicht aus Zellen hervorgegangen. İch möchte noch auf den zuletzt erwähnten Bंefund, das Hinüberwuchern der streifigen Lage auf die andere Seite oder vielmehr genauer zwischen zwei Blätter der sich spaltenden 
elastischen Lamelle hinweisen, (denn das scheint mir die natürlichste, ja die einzig mögliche Deutung zu sein); diess Hinüberwuchern kann nicht etwa durch die gewöhnlichen Wachsthumserscheinungen, Vermehrung der Zellen und alImähliches Auseinanderrücken derselben durch Zunahme der Intercellularsubstanz erklärt werden, denn dann müsste die Wucherung immer auf der inneren Seite der Lamelle bleiben; es muss hier vielmehr, falls wir nicht etwa das Entstehen der Zellen aus der elastischen Lamelle, d. b. aus Intercellularsubstanz zugeben wollen, angenommen werden, dass die grade auf der inneren Fläche der elastischen Lamelle am reichlichsten angehäuften runden Zellen letztere durchwandern vermittelst der feinen Kanälchen, und zwischen den gespaltenen Blättern derselben sich vermehren und zu spindel- oder sternförmigen Zellen ausbilden, die von etwas Intercellularsubstanz umgeben werden.

Die beiden wichtigsten Veränderungen, welchen diese Verdickungen unterliegen, sind Fettmetamorphose und Verkalkung. Nach Virchow*) beginnt erstere sowohl in der Tiefe bei dem eigentlichen Atherom, das aus den halbknorpeligen Platten hervorgeht, als auch an der Oberfläche bei der fettigen Usur, die sich an den gallertigen Flecken findet, in den Bindegewebskörperchen. „Innerhalb dieser Körperchen, demnach bei den festen Flecken scheinbar in den Lücken und Höhlen des Balken- und Maschennetzes, lagern sich neben den Kernen kleinste Fettkörperchen $a b$, die allmählich zahlreicher werden, so dass sich zuletzt dichte und grosse Körnchenzellen, oft von ganz sternförmigem Bau und mit anastomotischen Fortsätzen versehen, finden. Allein auch hier zeigt sich wieder eine Verschiedenheit, indem bei dem eigentlichen therom diese Körnchenzellen grösser und zahlreicher werden und endlich, während die Grundsubstanz zwischen ihnen erweicht, zu einem gemeinschaftlichen Heerde confluiren, in welchem sie sich schnell zu Körnchenkugeln umbilden und in einen Körnerbrei zerfallen, aus dem sich grössere Fetttropfen und Cholestearinkrystalle ausscheiden. In der Oberfläche und namentlich bei den mehr gallertartigen Flecken dagegen ist die Bildung der Körnchenzellen oft sehr unvollständig; die einzelnen Zellen entwickeln nur wenig Fett in sich und die Fettkörnchen liegen daher mehr zerstreut in der

*) Virchow, Gesamm. Abhandlungen. 503 .

Archiv f. pathol. Anat. Bd. XXXVI. Hft. 2. 
weichen Grundsubstanz." Dieser Darstellung kann ich nach meinen Untersuchungen nicht in allen Punkten beistimmen. Was zunächst den Satz anlangt, dass bei den halbknorpeligen Platten die fettige Entartung in der Tiefe, bei den gallertigen Verdickungen an der Oberfläche ihren Sitz hat, oder wenigstens beginnt, so konnte ich diesen Unterschied nicht bestätigen. Gallertige Verdickungen sind in Ganzen nur selten, und ich habe nicht Gelegenbeit gehabt, viele derselben zu untersuchen. Die Entartung fand sich dabei in denselben Schichten, wie bei den halbknorpeligen Platten, d. h. in Allen. Diess Verhältniss bei letzteren zu bestätigen, ist bei der Häufigkeit derselben sehr leicht; dass bei einem mehr oberflächlichen Sitze die Entartungsheerde nicht leicht so gross werden, wie bei einem tieferen, ist natürlich; denn die oberflächlichsten Schichten werden dabei früher ergriffen und der Entartungsheerd eröffnet sich ziemlich raseh. Allein selbst wenn man grössere Heerde an ihrer Grenze untersucht, so wird "man finden, dass die erste Entartung sich nicht immer unmittelbar da zeigt, "wo die Intima die Media berührt", wie Virchow*) will, sondern auch häufig in den mittleren Verdickungsschichten, in der Mitte zwischen Media und innerer Oberfläche; in dieser Gegend finden sich auch sebr' häufig kleinere Heerde fettiger Entartung, in denen Zellen und Intercellularsubstanz vollständig zu Grunde gegangen sind, und die nur desshalb den Namen eines Atheroms nicht verdienen, weil sie zu klein sind, um eine nach innen vorragende Geschwulst zu bilden; allein selbst grössere Heerde finden sich hier und in den oberflächlichen Schichten, während die tieferen, der Media zunächst gelegenen Schichten noch vollständig intact sind. Den eigentlichen Ausgangspunkt der fettigen Entartung bilden sowohl Zellen als Intercellularsubstanz; dass bei den tieferen Heerden zuerst jene, bei den oberflächlichen zuerst diese entarten, kann ich nicht bestätigen; beide fallen abwechselnd in den verschiedensten Tiefen der fettigen Entartung zuerst anheim. Dieser Verschiedenheit kann man übrigens auch keinen grossen Werth beilegen; denn bei demselben Heerde findet sich manchmal an einer Stelle die primäre Entartung der Zellen, an einer anderen die der Intercellularsubstanz. Die Entartung der Zellen studirt man am besten von deI

*) Cellularpathologie. 3. Aufl. 354. 
Flăche, da dieselben sich so in ihrer grössten Ausdehnung darbieten; das Fett tritt zuerst meist in Gestalt feiner meist farbloser, selten intensiv gelber Tröpfchen in der Zellsubstanz auf, sowohl bei den runden als den sternförmigen Zellen; die Entartung der letzteren stellt sich ganz ebenso dar, wie bei den sternförmigen Zellen der normal dicken Intima; bei den rundlichen Zellen treten die Fettkörnchen auch zuerst in der Peripherie auf, und umgeben kreisförmig den runden Kern, gleich der Zellsubstanz, häufig ungleichmässig um denselben angehäuft; eine Membran lässt sich dabei nicht erkennen; der Kern verschwindet erst später. Neben dieser Entartung zu Körnchenkugeln, die immer gròsser sind als die ursprüngliche Zelle, tritt noch eine Entartung der runden Zellen in toto zu grossen Fetttropfen auf, die nicht aus einzelnen Tröpfchen zusammengeflossen sind. Die erste Veränderung dieser granulirten Zellen besteht dabei in einer gelblichen Entfärbung, die namentlich bei Carminimbibition deutlich hervortritt; zugleich wird die äussere Begrenzungslinie sehr scharf und dunkel, wie an einem Fettropfen; dann hellt sich allmählich der körnige Inhalt auf, die Carminimbibition verschwindet vollständig und an die Stelle des matten Glanzes und der granulirten Beschaffenbeit tritt ein homogenes Ansehen und der eigenthümliche Glanz des Fettes. An einigen Heerden sah ich ausschliesslich an den runden Zellen diese eigenthümliche Entartung und in diesen Fällen auch der Entartung der sternförmigen Zellen vorhergehen. Diese Beobachtung widerspricht der gewöhnlichen Annahme, dass bei der fettigen Entartung das Fett zuerst in Form feiner Fetttröpfehen auftrete, die nach der Ansicht der meisten Autoren als solche immer fortbestehen und nicht zusammenfliessen sollen. Letztere Eigenthümlichkeit wird dann zur Unterscheidung der Degeneration von der Fettinfiltration von aussen benutzt, bei der die einzelnen Fetttröpfchen sofort zu grossen Tropfen zusammenfliessen sollen. Hier baben wir ein deutliches Beispiel von der directen Umwandlung je einer Zelle zu einem grossen Fetttropfen, ohne dass das Fett zuerst als körniges Fett. aufgetreten wäre; die Zelle geht dabei vollständig unter, so dass jedenfalls entschieden eine Entartung hjer vorliegt, und nicht etwa eine Infiltration der Zelle mit Fett, bei der erstere ihre charakteristischen Eigenthümlichkeiten nicht einbüsst oder wenigstens nach Verlust des Fettes wieder erlangen kann. 
Das Auftreten der fettigen Entartung der Intercellularsubstanz tritt am deutlichsten an Dickenschnitten getrockneter Präparate hervor; namentlich ist Carminimbibition hier sehr zu empfehlen. An Flächenschnitten, die an deı in Müller'scher Flüssigkeit erhärteten Arterien angefertigt wurden, konnte man zwar auch die primäre Entartung der Intercellularsubstanz beobachten, indem die schön imbibirten Netze der sternförmigen Zellen gegen die nicht mehr imbibitionsfähige, bräunliche, undeutlich faserige Grundsubstanz scharf und deutlich abstachen; allein Flächenschnitte erlauben nicht die scharfe Trennung der einzelnen Schichten der Grundsubstanz und der einzelnen Lagen der Zellen, wie Dickenschnitte. An letzteren sieht man deutlich, wie die fettige Entartung zuerst in der Mitte der die Zellenlagen trennenden Bindegewebszỉge auftritt und hier auch bei weiterem Fortschreiten zuerst ihr höchstes Stadium erreicht, während die Zellen noch sammt dem angrenzenden sie umgebenden hellen Hofe der Intercellularsubstanz erst später entarten. Es entsteht so das Bild eines Netzes mit in die Länge gezogenen, der. Oberfläche der Intima parallel gesteliten Maschen, in denen die normalen Zellen liegen, ungeben von der netzförmig entarleten Grundsubstanz. Auch hier finden sich zwei Arten der Fettentartung. In dem einen Falle ist die erste Veränderung eine Entfärbung des Gewebes, die namentlich bei Carminimbibition deutlich hervortritt; es wird gelblich, bräunlich, noch deutlich faserig; das faserige Ansehen verliert sich und es treten feine Körnchen auf, die zu grösseren Tropfen zusammenfliessen oder zu Krystallen zusammentreten. Im anderen Falle ist auch die Entfärbung des Gewebes und der Verlust der Fähigkeit der Carminimbibition das Erste; aber die befallenen Züge erhalten, ohne dass körniges Fett auftrete, sofort den eigenthümlichen Fettglanz, und setzen sich gegen die anstossenden noch nicht entarteten Lagen dureh dunkle Begrenzungslinien $a b$; zuletzt verschwindet das faserige Aussehen der Intercellularsubstanz und damit erbält die ganze Schicht das eigenthümliche Aussehen des Fettes. Nicht immer ist das Endproduct flüssiges tropfenförmiges Fett, sondern sehr bäufig krystallinisches. Meistens tritt dasselbe in den grossen leicht erkennbaren Tafeln des Cholestearins auf. Neben diesen finden sich sehr häufig grosse lange schmale Prismen von 0,008-0,012 Mm. Breite und sehr verschiedener Länge, die mit den breiteren Tafeln jedoch Aussehen 
und Grösse der Winkel vollständig gemein haben. Diese Prismen finden sich nicht selten in grösserer oder geringerer Anzabl mitten in der verdickten Intima, ohne dass in der Umgebung sich körnige Entartung der Intercellularsubstanz findet, während die Zellen noch vollständig normal sind. Es scheint daher dieses Fett aus directer Umbildung der Intercellularsubstanz entstanden zu sein; die Prismen liegen dabei bündelweise zusammen, die einzelnen Bündel durch roth imbibirte Intercellularsubstanz von einander getrennt, auf Dickenschnitten quer und schief in allen Richtungen, meist senkrecht auf die Oberfläche gerichtet, selten ihr parallel. Diese Rrystalle gleichen ganz denen, welche sich als Margarinkrystalle in den Handbüchern*) beschrieben und abgebildet finden. Ein regelmässiger Bestandtheil der Atherome ist ferner das Myelin, das aus den Schnitten der getrockneten Aorta beim Aufweichen in Wasser in grosser Menge hervorquillt und an seinen eigenthümlichen Formen und seiner Reaction gegen Wasser und Kali (Aufquellen und Zusammenziehen) leicht zu erkennen ist. Ob diess Fett auch bloss aus Entartung der Intercellularsubstanz hervorgeht, wie diess namentlich für Margarin leicht $\mathrm{zu}$ beobachten ist, lässt sich nicht entscheiden; der bekannte Cholestearingebalt desselben lässt es als wahrscheinlich erscheinen.

Fügen wir diesen Fettarten, Margarin, Cholestearin und Myelin noch die durch das Entarten der Zellen entstandenen Körnchenbaufen (uneigentlich Körnchenzellen, da die Zellen dabei vollständig zu Grunde gegangen sind und sich nicht mehr nach Entfernung des Fettes wieder regeneriren können) und Fetttropfen hinzu;, sowie die Stücke erweichter oder nekrotischer Grundsubstanz, welcher durch fettige Entartung der Umgebung das Ernährungsmaterial zu frühzeitig abgeschnitten worden ist, so hätten wir damit die Endproducte der fettigen Entartung.

Die fettige Entartung befällt sowohl die gleichmässig als die ungleichmässig verdickte Intima, sowohl in grösserer Ausdehnung als in einzelnen kleineren Heerden. Ist sie in der gleichmässig verdickten Intima über grössere Strecken verbreitet, so ähnelt sie der Form, in welcher die normal dicke Intima meistens entartet. Wie aber auch bei letzterer kleinere Entartungsheerde vorkommen,

*) Harting, Das Mikroskop. S. 470. Fig. 204 A. 
so finden sie sich auch in der gleichmässig verdickten Intima. Das Schicksal derselben hängt von ihrem Sitze ab; in der Nähe der Oberfläche befindliche Heerde werden selten so gross, wie die in der Tiefe und letztere können wohl ebenso, wie die fettige Entartung der normal dicken Intima, starke Hervorragungen nach innen erzeugen, da die entstehenden Fettmassen meist voluminöser sind, als die Gewebe, aus denen sie entstanden; solche Fälle werden hauptsächlich den Anschein geben, als ob die tiefsten Lagen, die am stärksten entarteten sind, auch am mächtigsten gewuchert gewesen seien. In den circumscripten Verdickungen sind die Heerde natürlich beschränkter, doch darf man sich das Verbältniss durchaus nicht so denken, als ob der Heerd zuerst an der Stelle der stärksten Verdickung auftrete oder auch nur an die Verdickung selbst gebunden sei; man findet denselben nicht selten, wenigstens im Beginne, am Rande der Verdickung, wo letztere mehr oder weniger steil gegen die weniger verdickte Intima abfällt, und grössere Heerde sind oft gar nicht auf die Verdickung beschränkt, sondern erstrecken sich auch gleichmässig auf die benachbarte, weniger verdickte (bei den Hirnarterien normal dicke) Intima, während die verdickte Stelle der Intima nicht vollständig entartet ist; dadurch erbalten die einzelnen Verdickungen sowohl als die ganze Intima ein unregelmässiges, marmorirtes Aussehen. Wucherungsheerde und Entartungsbeerde entsprechen sich also durchaus nicht vollkommen, so dass der Zweifel wohl gerechtfertigt erscheint, ob diese Fettmetamorphose ein der Verdjckung sich unmittelbar anschliessender Prozess sei und so den Prozess den entzündlichen annähert, wie diess Vircbow behauptet.

Die ersten Anfänge des Prozesses sind mikroskopisch und werden erst, wenn die Intercellularsubstanz in ausgedehnterer Weise entartet ist, dem unbewaffneten Auge durch eine mehr oder weniger intensive gelbe Färbung und Trübung der Intima sichtbar. Die kleinsten Heerde sind verschieden gestaltet, je nachdem körniges oder krystallinisches Fett zuerst auftritt. In ersterem Falle sind die Heerde mehr länglich, und halten sich an die der Oberfläche parallele Schichtung der Intima, so dass sie hier wohl als eine Aneinanderreihung einzelner kleinerer Heerde angesehen werden können, deren jeder einem sogenannten Zellenterritorium entspräche. Im zweiten Falle dagegen ist die Gestalt des Heerdes 
unregelmässiger, er durchsetzt mehrere Schichten in senkrechter Richtung, während er der Oberfläche parallel sich weniger weit ausdehnt; hier ist er nicht an die idealen Zellenterritorien gebunden, sondern zeigt gar keine Beziehung zu denselben; sonderbar ist es, dass manchmal an einzelnen isolirt und auf die Oberfläche senkrecht liegenden längeren Fettkrystallen die nächsten Zellen derselben parallel gestellt sind, also den Verlauf der übrigen Schichten senkrecht durchschneiden. Betrachtet man die Grenzen grösserer Heerde, so findet man manchmal auch noch hier, dass sie sich nicht an die Zellenterritorien halten; die Grenze eines Heerdes durchziebt die streifigen Schichten in schiefer Richtung, nach der inneren Oberfläche aufsteigend, als eine Zone, in der das Intercellulargewebe durch Einlagerung feiner Fettkörnchen bräunlich gefärbt ist, während die daselbst befindlichen runden oder sternförmigen Zellen, die ganz verschiedenen Schichten angehören, vollkommen intact sind und die ihnen zugehörigen Territorien der Intercellularsubstanz mit der einen Hälfte dem Entartungsheerde, mit der anderen dem normalen Gewebe angehören.

Ich habe bei dieser Darstellung nur den anatomischen Befund als Richtschnur angenommen; ich babe die Fettmetamorphose der normal dicken und der verdickten Intima scharf geschieden oder, um mit der Schule zu sprechen, „die einfache Fettmetamorphose, welche ohne ein weiter erkennbares Vorstadium eintritt“, und "die Vorgänge, wo wir vor der Fettmetamorphose ein Stadium der Reizung unterscheiden können." Ich bin hierin nur Virchow ge$f_{0}$ lgt, dessen in seinen gesammelten Abhandlungen gegebener Darstellung ich nur Weniges hinzufügen konnte. Anders und viel schematischer findet sich dieser Gegenstand in der Cellularpathologie (3. Aufl. S. 322 u. 351 u. ff.) behandelt, ich weiss nicht, ob auf Grund erneuter Untersuchungen. Die Fettmetamorphose mit vorhergegangenem Reizungsstadium oder die Endarteriitis ist hier vollständig mit den tiefen Entartungsheerden der verdickten Intima, den eigentlichen Atheromen der Alten, identifieirt, während die in der Nähe der Oberfläche stattfindenden fettigen Metamorphosen alle der einfachen fettigen Degeneration zugewiesen werden; letztere führen zu der fettigen Usur, die kein Geschwür im eigentlichen Sinne des Worts ist, erstere zu dem atheromatösen Geschwür. Weiter heisst es, dass „die verschiedenen Prozesse sich 
gelegentlich in demselben Falle gleichzeitig finden. Neben den charakteristischen Umwandlungen der chronisch entzündlichen Theile in der Tiefe finden sich an der Oberfläche nicht selten einfach fettige Veränderungen." Es beruht diese Darstellung auf dem Irrthum, dass bei den Verdickungen die oberflächlichsten Schichten unberührt blieben und bloss die tiefen wucherten; dass diess durchaus falsch ist, habe ich oben auseinandergesetzt; es ist auch an und für sich bei einer Verdickung von $2 \mathrm{Mm}$. unwahrscheinlich, dass sie bloss durch Wucherung der tiefen, an elastischem Gewebe reichen Schichten der im normalen Zustande kaum 0,05 Mm. dicken Intima entstanden sei, während die oberflächlichen streifigen Lagen noch unverdickt über die verdickte Stelle hinzögen; dafür wird man wohl nie ein beweisendes Präparat erbalten; genaue Untersuchungen werden in der Mehrzahl der Fälle eher das Gegentheil darthun. Wenn wir daher die Form der parenchymatösen Entzündung hier für zulässig halten, so werden wir als Endarteriitis alle in der verdickten Intima vorgehenden feltigen Metamorphosen auffassen müssen; denn allen geht ein Reizungsstadium, d. h. ein Wucherungsprozess in der Intima vorher. Ich habe jedoch schon oben Zweifel geäussert, ob beide Prozesse unmittelbar mit einander in Verbindung gebracht werden müssen, ob sie durch Einen Entzündungsreiz hervorgebracht worden sind, oder ob nicht die Fettmetamorphose in einer schon Jahre lang bestehenden Verdickung. unabbängig von dem Prozess der Verdickung selbst entstebt. Als Beispiel solcher Fälle möchte ich besonders manche fettjge Entartung in der mehr gleichmässiger verdickten Intima anführen, wenn in letzterer, wie es meistens der Fall ist, der Prozess der Verdickung abgelaufen ist und das Gewebe nur sternförmige und keine jugendlichen, runden Zellen enthält; in diesem Fall können, wie schon erwähnt, auch wirkliche, in das Lumen des Gefässes hervorragende Atherome entstehen. Mehr dem Bilde einer Endarteritis entsprechen die Fälle, wo sich die fettige Entartung direct an den Wucherungsprozess anschliesst, d. h. eine mit zahlreichen jugendlichen zelligen Elementen erfüllte Intima befällt. Grade die oberfächlichen fettigen Entartungen dürfte man fast alle hierher zählen, besonders die in den circumscripten Wucherungsheerden, den sogenannten halbknorpeligen und gallertigen Auflagerungen auftretenden, denn grade die oberflächlichsien Schichten enthalten in 
der Regel die meisten jungen Zellen. Die eigentlichen Atherome dürften nur einen kleinen Theil der Endarteritis bilden. Auch bei Virchow finden sich Andeutungen, dass er auf diese unmittelbar vorhergehende Zellenwucherung das Hauptgewicht legt. Siehe Figur 128, pag. 356 sammt Erklärung in der Cellularpathologie. Mein abweichendes Resultat liegt bloss darin, dass ich diese Zellenwucherung seltener in den tieferen Schichten, viel stärker in den mittleren und oberflächlichen der Fettentartung vorhergehen sehe. Damit fällt auch der Unterschied zwischen der oberflächlichen fettigen Usur und dem tiefen atheromatösen Geschwür, da Art des Zustandekommens sowohl wie Endproducte bei beiden gleich sein können.

Kürzer kann ich über die Verkalkung hinweggehen, deren Verhältnisse ausführlicher von Förster (Handbuch 2. Aufl. II. 749) geschildert sind. Auch sie tritt in allen. Schichten der Intima auf, jedoch werden die oberflächlicheren Heerde nie sebr umfangreich, die grösseren Kalkplatten gehören, auch wenn sie bis zur Oberfläche durchgedrungen sind, ursprünglich den mittleren oder tieferen Schichten an; an ibrem Rande werden sie noch auf die Strecke von $0,5-2 \mathrm{Mm}$. und mehr von den oberflächlichen nicht verkalkten Schichten überzogen; oft finden sich die oberflächlichen Schichten verkalkt, die tieferen dagegen $z \mathfrak{u}$ einem atheromatösen Brei erweicht, wie diess Förster schildert. Das Gewebe in ibrer Umgebung befindet sich meistens im Zustand der fettigen Metamorphose, und in den Kalkplatten selbst tritt nach Auszug der Kalksalze ganz das Gewebe der verdickten Intima hervor, welches hier und da selbst vollständige Atheromberde enthält, die sich schon makroskopisch an der mehr oder weniger intensiven gelben Trübung der Kalkplatten erkennen lassen. Die Kalkplatten entstehen also durch eine Ablagerung von Kalksalzen in die vorhandenen Gewebe, wie auch Förster behauptet. Nach Virchow dagegen sollen die Kalkplatten verästelte zackige Körperchen enthalten, meist etwas kleiner und weniger stark verästelt, auch weniger dicht gelegen als Knochenkörperchen. An feinen Schliffen sieht man allerdings in der homogenen Substanz zahlreiche kleine, oft mit Fetttröpfchen gefüllte Lücken von ausserordentlich unregelmässiger zackiger Gestalt, die jedoch nicht die mindeste Aehnlichkeit mit Knochenkörperchen, geschweige mit den grossen. Zellen der ver- 
dickten Intima haben; mit Carmin lässt sich in ihnen kein körperliches Element nachweisen. Finden sich wirklich die Zellen von der Verkalkung frei, so wäre diess ebensowenig eine Knochenbildung, wie die Verkalkung des Knorpels; man müsste dann erst noch den lamellösen Bau des Knochens nachweisen und zeigen, dass auch nach der Entkalkung sich dieses Gewebe von dem unverkalkten Gewebe der Intima unterscheidet, dass also hier wirklich Neubildung eines differenten Gewebes vorliegt. Jedenfalls möchten diese Fälle nicht die häufigsten sein gegenüber der reinen Verkalkung und ich glaube daher nicht, dass man die Verknöcherung als regelmässigen Ausgang der Endarteriitis betrachten kann.

\section{3) Veränderungen der Media.}

Die Media *) ist bei so tiefgreifenden Störungen in der Intima, wie die eben besprochenen, immer betheiligt. Zunächst fällt ibre ausserordentlich verschiedene Dicke in das Auge; nur einmal habe ich sie bei einer Verdickung der Intima von $0,5 \mathrm{Mm}$. so ziemlich normal dick (1,2 Mm.) gefunden; bei allen anderen Messungen war sie erheblich verdünt, meistens betrug ihre Dicke 0,6-0,7 Mm., im Minimum 0,4 Mm., d. h. ohne selbständige pathologische Prozesse in ibr. In Verbindung damit ist auch gewöhnlich die Zabl der abwechselnden Muskel- und elastischen Lagen vermindert, indem sie zwischen 30 und 45 beträgt, (die normale Zahl schwankt zwischen 50 und 60). Die Thatsache, dass die Zahl der Muskellagen durchaus nicht immer im Verhältniss zu der ganzen Dicke der Media steht, d. h. mit ibr zu- oder abnimmt, beweist, dass es sich hier nicht in jedem Fall um denselben Prozess handelt. Die Fälle, wo die Dicke der Media bei normaler Zahl der Muskellagen nur wenig abgenommen hat (ich fand z. B. bei der Dicke der ganzen Membran von 0,7 and $0,75 \mathrm{Mm} .48$ und 50 Lagen), mögen wohl als einfache Atrophie durch Druck bezeichnet werden; hier streift die Zahl nahe an das Normale heran, während die Dicke der einzelnen Schichten und zwar hauptsächlich auf Kosten der Muskelelemente erheblich sich vermindert hat; diess ist jedoch selten. Am nächsten stehen die Fälle, wo ausser der verminderten Anzahl der Schichten nichts

*) Auch das Folgende bezieht sich, wo nicht ausdrïcklich anders bemerkt, auf die Aorta. 
Besonderes wahrzunehmen ist; hier sind die der Intima zunächst gelegenen Schichten geschwunden,' während die Dicke der übrigen sich ebenfalls vermindert hat, und zwar in der Weise, dass die äusseren, der Adventitia benachbarten Schichten, noch breiter sind, als die inneren. Es würde dem wirklichen Befunde nicht entsprechen, wenn man behaupten wollte, dass diese Fälle nur bei stärkeren Verdickungen der Intima vorkommen als die ersten. Ausserdem finden sich noch Veränderungen, die auf das physiologische Verbalten der Arterienwand von grossem Einfluss sein müssen; das gegenseitige Dickenverhältniss der elastischen und Muskelschichten ist nämlich in den meisten Fällen alterirt, nich Ł bloss dadurch, dass unter dem Druck von der verdickten Intima die Muskellagen bei gleichbleibender Dicke der elastischen geschwunden sind, sondern letztere wuchern auch selbständig und bewirken natürlich noch fïr sich eine oft sehr weitgehende Atrophie der Muskulatur. Sie nehmen an Breite zu und zerfasern sich zugleich, so dass zwischen einem faserigen Gewebe, das sich durch seine Reactionen als elastisches ausweist, nur in gewissen Entfernungen kleinere und grössere schmale Streifen einer für Carmin roth imbibitionsfähigen Substanz mit oder ohne längliche Kerne übrigbleiben, die Reste der Muskelschichten; eine Neubildung von Zellen in dem elastischen Gewebe lässt sich nicht nachweisen. Zuletzt verschwinden diese Reste der Muskulatur und das in feine Fasern aufgelöste elastische Gewebe nimmt deren Stelle ein. Ebenso wie die oben behandelten Veränderungen finden sich diese zunächst in den der Intima anstossenden Schichten zuerst und diese ist dann von der eigentlichen Muscularis durch eine verschieden dicke der Media angehörige Schicht elastischer Fasern getrennt.

Dieser Schwund der Muskelfasern geht meistens ohne Fettmetamorphose vor sich; es ist eine insensible Atrophie, die erst an ihren Resultaten zu erhennen ist. Nur wenn die Fettentartung oder Verkalkung in der Intima die tiefsten Schichten betrifft, babe ich in den benachbarten Lagen der Media Anhäufung von körnigem, tropfenförmigem und krystallinischem Fett bemerkt, ohne jedoch den Ausgangspunkt jedesmal sicher constatiren zu können. Das Bild, welches Förster in seinem Atlas der mikroskopischpathologischen Anatomie (XVIII., 2, b.) gibt, scheint für Entartung der Muskelzellen zu sprechen. 
Diese Veränderungen treten nur secundär auf bei und in Folge der hochgradigen Verdickung der Intima. Es finden sich aber in der Media noch andere, bisher wenig beschriebene Zustände, die sich mit den Erkrankungen der Intima verbinden, wie auch allein vorkommen, nehmlich die Umbildung der MuskeJfasern zu einem zellenreichen Bindegewebe und die selbständige Wucherung der elastischen Elemente mit nachfolgender Atrophie der glatten Muskelfasern. Die Bildung von Bindegewebe*) habe ich in der Aorta eines 48jährigen Mannes an mehreren Stellen, besonders in der aufsteigenden Aorta beobachtet, zugleich mit bochgradiger Verdickung der Intima; doch liegt in dem Prozess kein Grund, wesshalb er nicht auch allein vorkommen könnte. Jene Complication hatte jedoch die Folge, dass makroskopisch die Veränderungen der Media nicht erkannt werden konnten; ich fand sie erst an mikroskopischen Schnitten; da, wo die Media unter der Neubildung von narbigem Bindegewebe sehr geschwunden war, sah man nur eine tiefe Einziehung in der Intima; es ist jedoch klar; dass selbst die stärkeren Veränderungen an der frischen Aorta nur auf dem Durchschnitte zu erkennen sind. Die Bindegewebsbildung war an allen Stellen nur auf geringe Strecken ausgedehnt; in den meisten Fällen findet sie sich zuerst in den der Intima benachbarten Schichten oder schliesst sich vollständig den tieferen Schichten der Intima an, so dass man manchmal im $Z$ weifel sein kann, ob das Bindegewebe nicht etwa von der Intima aus in die Media hineingewuchert sei und die Elemente der lelzteren bloss durch Druck verdrängt habe. Abgesehen davon, dass in den angrenzenden Schichten der Media sich meist bestimmte Veränderungen vorfinden, welche, wie Zellenbildung, für eine Betheiligung derselben sprechen, sieht man manchmal, dass das für die tieferen Schichten der Intima gehaltene Bindegewebe mit den oberflachlichsten Muskelschichten in continuirlichem Zusammenhange steht, oder dass es von der eigentlichen Intima noch durch eine verschieden dicke Lage elastischen Gewebes getrennt ist, welches die durch Schwund der Muskelelemente übrig gebliebenen innersten elastischen Lamellen der Media darstellt. Ich glaube daher, dass alle in der Media befindlichen bindegewebigen Neubil-

*) Siehe Wedl a. a. 0. S. 12. 
dungen durch Umwandlung der Elemente dieser Membran hervorgegangen sind und erst später mit den tiefen Lagen der Intima in continuirlichen Zusammenbang treten. Gleiches gilt für ihr Verbältniss zu der Adventitia, in deren Nähe sich selten und meist bloss bei den höheren Graden Bindegewebe in der Media findet. Ferner finden sich auch in den mittleren Sehichten der Media bindegewebige Stränge von Intima und Adventitia durch zahlreiche Lagen normaler Media getrennt, auf welche jene Bedenken keine Anwendung finden können. Tritt das̄ Bindegewebe in compacteren Massen auf, so durchziehen die Stränge desselben die Media entweder ihrer Schichtung mehr oder weniger parallel, oder mehr in senkrechter Richtung; dabei senden die grösseren Stränge in die Umgebung mehr oder weniger tief 'greifende Wurzeln hinein, welche denselben oft das Ansehen mikroskopischer sternförmiger Narben geben. Die der Oberfläche parallel verlaufenden Stränge haben eine grössere Flächenausdehnung, eine geringere Dicke, die anderen finden sich nur an sehr circumscripten Stellen, an denen sie die Media senkrecht durchsetzen, etwa $0,7 \mathrm{Mm}$. lang und 0,2 $\mathrm{Mm}$. breit; auf der einen Seite erreichen sie die Adventitia, in der sich dann ebenfalls Zellenbildung findet, an der anderen die tieferen Schichten der Intima oder nur jenes. erwähnte, von letzteren durch elastisches Gewebe getrennte, bindegewebige Stratum. Das Bindegewebe besteht überall in einer hellen, leicbt faserig erscheinenden oder in Bïndel angeordneten Grundsubstanz, in der eine verschiedene Zahl elastischer Fasern und sehr zahlreiche, dicht gelegene, kleine zellige Elemente eingelagert sind. Die elastischen Fasern sind Reste der elastischen Lamellen der Media und finden sich mehr an der Grenze des Bindegewebes, weniger in der Mitte desselben. Die Zellen sind kleiner als die Muskelkerue, rundlicb, oval, länglich und sternförmig, stark glänzend und für Carminimbibition leicht empfänglich. Sehr wichtig ist eine genaue Betrachtung der Grenzzone der Media gegen das Bindegewebe hin, welche nur an sehr dünnen Schnitten möglich ist; diese müssen mit besonderer Sorgfalt angefertigt werden, da der Zusammenhang der Membran an dieser Stelle meist sehr gelockert ist. Es handelt sich zunächst um das Verbältniss der Bindegewebszellen zu den contractilen Faserzellen. Wem sich auch das Hervorgehen jener aus diesen oder wenigstens ihren Kernen nach- 
weisen lässt, so kann doch auch nicht die Möglichkeit geleugnet werden, dass jene zum Theil aus etwaigen zelligen bindegewebigen Elementen der Media durch Wucherung entstünden, falls das Vorhandensein letzterer nachgewiesen wäre. Diess ist aber bis jetzt nicht der Fall, und auch mir war es nicht möglich, durch die 2wei Methoden, vermittelst deren ich die Zellen in der Intima darstellte, durch Behandlung. mit Müller'scher Flüssigkeit oder Silberlösung, in der Media ausser den Muskelzellen andere zellige Elemente nachzuweisen. Die Grenzzone der Media nimmt sich nun verschieden aus. Die erste Veränderung in der Media ist in manchen Fällen eine Verbreiterung der elastischen Lamellen, die sich zugleich in feine Fasern auflösen; die Muskelschichten werden entsprechend schmaler, so dass in der nächsten Umgebung des Bindegewebes sich undurchsichtiges dunkles elastisches Gewebe angehäuft findet, in dem man noch zerstreut schmale Streifen einer roth imbibirten Substanz mit dunkleren, stäbchenförmigen Körperchen (Kernen) erkennt, die Reste der Muskelzelien, oder es finden sich in dem elastischen Gewebe nur einige helle, rundliche, etwas granulirte oder längliche, sehr schmale Körperchen, deren Natur als Kerne oder Reste der Muskelsubstanz nicht immer deutlich ist. Unter Zunahme der. roth imbibirten faserig werdenden Substanz nehmen die Körperchen an Zabl zu, runden sich ab, das elastische Gewebe schwindet, oder man sieht direct einen Zug elastischen Gewebes mit länglichen Körperchen (Kernen oder Zellen) in faseriges, durch Essigsăure sich aufhellendes Gewebe nit zahlreichen Zellen übergehen, wobei nur wenige elastische Fasern sich erhalten. In vielen anderen Fällen sieht man einen directen Uebergang der Muskelelemente in das Bindegewebe; die Muskelkerne schwellen dabei an, vermehren sich stark zu rundlichen oder ovalen Elementen, so dass die elastischen Lamellen stellenweise gleichsam Schläuche von" runden, kleinen Körperchen umschliessen, die breiter sind, als die normalen Muskelschichten in der nächsten Umgebung. Die elastischen Lamellen werden dabei schmaler, spalten sich in feine Fasern von unregelmässigem Verlauf, die unter fortwährender Vermehrung der Kerne allmählich sparsamer werden. Zwischen den Kernen (ader Zellen) tritt ein bei Essigsäure sich aufhellendes, mit Carmin sich schwach imbibirendes Gewebe auf, welches zuletzt feinstreifig oder faserig und nicht mit Carmin im- 
bibirt, mit zahlreichen runden oder ovalen Körperchen und ohne elastische Fasern übrig bleibt. Diese Beobachtungen lassen natürlich noch Manches unaufgeklärt; das Entstehen der Bindegewebskörperchen aus den Muskelkernen wird hierdurch festgestellt, wie ich schon hervorgehoben habe, dagegen ist das Schicksal der Zellsubstanz der Muskelzelle urklar; ein grosser Theil derselben schwindet in vielen Fällen, ein Theil derselben bleibt vielleicht zurück, den Kern umgebend, und später mit ihm die Bindegewebszelle zusammensetzend; ein anderer löst sich vielleicht direct in die faserige Intercellularsubstanz des Bindegewebes auf; denn so lässt sich die Beobachtung, dass eine Muskellage durch Wucherung der Kerne, zwischen denen immer noch etwas belle Substanz ubrig bleibt, und durch Zunahme der letzteren in Bindegewebe übergeht, am leichtesten epklären. Wie dem auch sei, sicher ist auf der anderen Seite, dass auch das elastische Gewebe sich direct in die Intercellularsubstanz des Bindegewebes wieder umbilden kann, aus der es ja entstanden ist; eine fettige Metamorphose habe ich dasselbe bei diesen Prozessen nie eingehen sehen.

Eine directe Umbildung der Muskelfaserzellen zu rundlichen Bindegewebszellen konnte ich verschiedene Male an den Arterien der Hirnbasis constatiren. Schon bei der gewöhnlichen Verdickung finden sich bier auf der äusseren Fläche der tiefen elastischen Lamelle der Intima kleine rundliche, helle, granulirte Zellen von $0,005 \mathrm{Mm}$. Durchmesser in einer mehr homogenen Zwischensub$\operatorname{stanz}$, die nicht so stark mit Carmin imbibirt sind, wie die eigentlichen Muskelzellen; daneben spindelförmige Zellen- (Uebergangsformen zu den Muskelzellen), der Zusammenhang der Media mit der Intima ist daselbst stark gelockert; auch in der Mitte der Media finden sich solche Stellen. An andern Präparaten war die Media ganz in der Bildung solcher Elemente untergegangen, und zwar mit und ohne Verdickung der Intima; ist letztere verdickt, so findet sich die erste Veränderung meist an dem elastischen Band. Die rundlichen Zellen haben die obige Grösse; lassen neben der dunkel imbibirten (uhrglasförmigen) Zellsubstanz noch einen helleren Kern mit körnigem Inhalt und Kernkörperchen unterscheiden; Zellen und Kern scheinen in lebhafter Theilung begriffen zu sein (doppelte Kernkörperchen, Bisquitform etc.). Neben diesen finden sich noch spindelförmige Zellen, 0,003-0,005 Mm. breit 
und $0,01 \mathrm{Mm}$. und mehr lang; diese finden sich meist an der Uebergangszone in die normale Media und gehen direct in die Muskelzellen über, indem sie an Breite und Länge zunehmen und das zwischen innen befindliche helle leicht faserige Gewebe schwindet; auf der andern Seite finden sich alle Uebergänge zwischen den spindelförmigen und runden Zellen. Oder die spindelförmigen Zellen bilden verschiedene Züge, welche die Media mehr oder weniger schief durchsetzen und sich untereinander vereinigen, und zwischen denen die rundlichen Zellen in kleineren Gruppen angeordnet liegen; indem in der Grenzzone sich spindelförmige, der Intima parallele, längere und kürzere Zellen finden und das helle Zwischengewebe schwindet, geht diese Stelle in die normale Media über. Die Dicke der Media war durch diese Veränderung nirgends alterirt.

Während diese Prozesse nur unter dem Mikroskop beobachtet wurden, fand ich all der lliaca communis und exteraa der rechten Seite einer 59jährigen Frau eine Wucherung der elastischen Elemente in der Media, welche schon für das blosse Auge an ihren Folgen erkennbar war. Von einem an der hinteren Seite der Arterie herablaufenden, in das Innere hervorragenden schmalen Wulste liefen zablreiche stark ausgeprägte, quer verlaufende Falten aus, welche, das Lumen der Arterie vollständig umgebend, an beiden Seiten des Wulstes endigten und so bloss diesen selbst frejliessen. Bei der Untersuchung ergab sich Folgendes: Der Längswulst wird von Intima und Adventitia gebildet, von denen 'die erstere sich bis zu 0,4 Mm., die letztere (bei einer normalen Dicke von $0,5 \mathrm{Mm}$.) bis zu 1,2 $\mathrm{Mm}$. verdickt; jedoch findet sich an dem mikroskopischen Präparate die Hervorragung nicht nach innen, sondern nach aussen, der Adventitia zu. Im übrigen Theile der Arterie ist die Intima in viel geringerem Grade, höchstens bis zu $0,1 \mathrm{Mm}$. verdickt, und bewirkt also keine bedeutende Unebenheiten; das faltenartige Ansehen der Intima rührt von einer Unwandlung der Media her, deren Dicke zwischen 0,25 und 0,5 Mm. schwankt. Während die normale Media der lliaca durch schmale Züge elastischen Gewebes in $12-15$ verhältnissmässig breite $(0,025$ bis $0,06 \mathrm{Mm}$.) Schichten von Muskelgewebe getheilt ist, die der Oberfläche parallel verlaufen, ist dieser regelmässige Bau an dieser Iliaca ganz geschwunden; die Muskelelemente, an ibrer Carmin- 
imbibition zu erkennen, haben an Zahl und Volumen bedeutend abgenommen, das elastische Gewebe dagegen ist bedeutend vermehrt. Auf dem Längsschnitt sieht man letzteres in Form von dunkel und scharf conturirten, rundlichen, ovalen oder wurstförmigen Gebilden von sehr verschiedener Breite bis zu 0,006 Mm. und etwas darüber, deren äussere Conturen nicht regelmässige kreisförmige oder elliptische Linien bilden, sondern aus zahlreichen aneinander gereihten kleineren Kreissegmenten zusammengesetzt sind; dieses so wie der weitere Umstand, dass die grössten Gebilde auf der Fläche stark netzförmig schattirt sind, lassen es als wahrscheinlich erscheinen, dass diese grösseren elastischen Gebilde aus feineren zusammengeflossen sind. Das roth imbibirte Gewebe zwischen diesen ist an verschiedenen Stellen in sehr verschiedener Menge vorhanden und entbält kleine, dunkel imbibirte, glänzende Körperchen, deren Durchmesser viel kleiner ist $(0,0025 \mathrm{Mm}$.) als der der normalen Kerne der Muskelzellen; sie sind selten von runder, häufig von mehr länglicher, gebogener oder gezackter Gestalt. Diese Substanz durchzieht in verschieden breiten Zügen das elastische Gewebe der Media in verschiedenen Richtungen, senkrecht dasselbe durchschneidend oder der Intima mehr oder weniger parallel; oft vereinigen sich solche Züge zu mehr sternförmigen Figuren, die nach verschiedenen Seiten hin ausstrahlen. An mehreren Stellen scheint eine Wucherung der Kerne vor sich zu gehen, sie liegen ausserordentlich dicht und haben eine etwas bedeutendere Grösse. Wo die Media am schmalsten ist, findet sich das meiste elastische Gewebe und die geringste Menge der roth imbibirten Substanz. Auf dem Querschnitt der Arterie erscheint die Media in ihrem Bau der normalen mehr genähert, insofern sie noch im Ganzen aus der Intima parallelen Schichten besteht. Das elastische Gewebe zeigt sich auch hier stark vermebrt, ist aber mehr längsstreifig; es besteht also hauptsächlich aus quer verlaufenden, untereinander zusammenfliessenden Fasern. Das roth imbibirte Gewebe, die Reste der Muskulatur, liegt zwischen den elastischen Faserziigen, scharf begrenzt, in Form langer und kurzer spindelförmiger Körperchen, deren Breite etwa dem Durchmesser der auf dem Längsschnitte sichtbaren Körperchen entspricht; an einigen Stellen wird die Lagerung unregelmässiger, indem die spindelförmigen Körper auch sehief auf die innere oberfläche ziehen. 
Diese eben beschriebene Veränderung ist, als Wucherung der Intercellularsubstanz mit nachfolgender Atrophie und Schwund der Zellen, jedenfalls etwas sehr Auffallendes und stimmt wenig mit den jetzt herrschenden Ansichten über das gegenseitige Verhältniss beider Substanzen überein. Uebrigens wäre es voreilig, jetzt schon ein Endurtheil uher sie abzugeben, da die Betheiligung von bindegewebigen Elementen an der Bildung der Media noch nicht hinreichend genug erforscht ist.

\section{Erklärung der Abbildungen.}

Tafel V.

Fìg. 1. Sternförmige Zellen in der Intima eines 10jährigen Knaben, Flächenschnitt nach Aufbewabren in Mutller'scher Flüssigkeit. $450: 1$.

Fig. 2. Dessgleichen aus der Intima eines 21 jährigen Mädchens. $450 ; 1$.

Fig. 3. Flächenschnitt der Intima eines 50-60jährigen Mannes. Müller'sche Flüssigkeit. $450: 1$.

Fig. 4. Sternförmige Zellen aus der Intima eines 50jährigen Mannes, mechanisch isolirt. Müller'sche Flüssigkeit. $450: 1$.

Fig. 5-7. Flächenschnitte der mit Silber behandelten Intima von einem 43jährigen Manne. Fig. 5, normal dicke Intima. 300:1. Fig. 6, Verdickte Intima. $200: 1$. Fig. 7, dessgleichen. $150: 1$.

Fig. 8. Zellen aus der verdickten Intima eines 38jährigen Mannes. Müller'sche Flüssigkeit. $300: 1$.

Fig. 9. Flächenschnitt derselben Intima. $300: 1$. Müller'sche Flüssigkeit.

Sämmtliche Abbildungen sind der Aorta entnommen. 

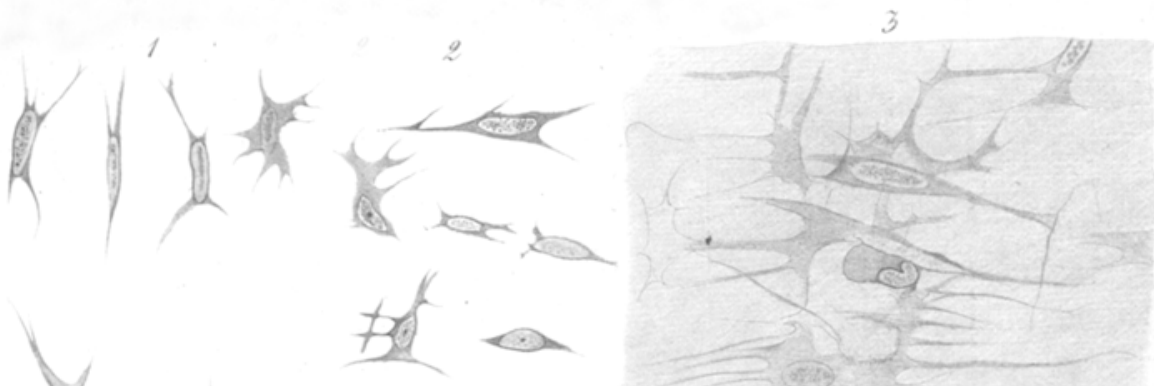

48
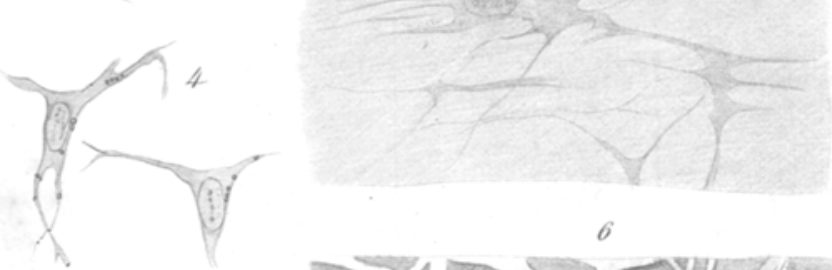

$$
5
$$
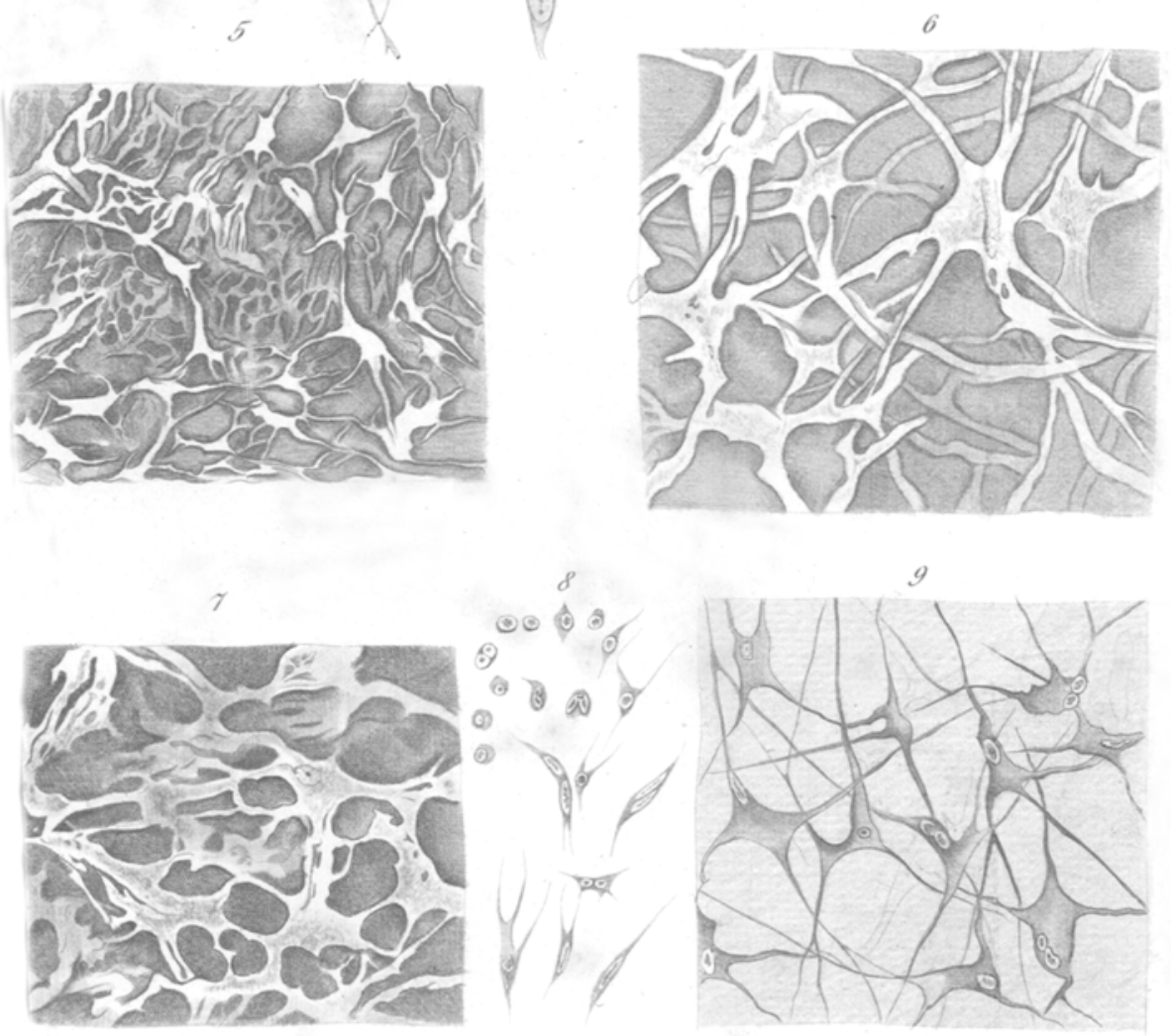